Portland State University

PDXScholar

Winter 3-30-2015

\title{
Exploring Dietary Sacrifice in Intimate Relationships for Couples with Celiac Disease
}

Lindsey Marie Alley

Portland State University

Follow this and additional works at: https://pdxscholar.library.pdx.edu/open_access_etds

Part of the Social Psychology Commons

Let us know how access to this document benefits you.

\section{Recommended Citation}

Alley, Lindsey Marie, "Exploring Dietary Sacrifice in Intimate Relationships for Couples with Celiac Disease" (2015). Dissertations and Theses. Paper 2255.

https://doi.org/10.15760/etd.2252

This Thesis is brought to you for free and open access. It has been accepted for inclusion in Dissertations and Theses by an authorized administrator of PDXScholar. Please contact us if we can make this document more accessible: pdxscholar@pdx.edu. 
Exploring Dietary Sacrifice in Intimate Relationships for Couples with Celiac Disease

$$
\text { by }
$$

Lindsey Marie Alley

A thesis proposal submitted in partial fulfillment of the requirements for the degree of

\author{
Master of Science \\ in \\ Psychology
}

\author{
Thesis Committee: \\ Cynthia D. Mohr, Chair \\ Kimberly Kahn \\ Eric Mankowski
}

Portland State University 2015 


\begin{abstract}
Prior research on eating behaviors has shown that romantic partners actively merge their dietary preferences throughout the course of a relationship and find significant value in cooking and eating the same foods together at the same times. Yet, little is known regarding the impacts of specific dietary support processes involved in maintaining said communal diet when one partner drastically alters his or her eating patterns. The current study defined dietary sacrifice as a phenomenon within the context of Celiac Disease (CD): a chronic illness that requires strict adherence to the gluten-free diet (GFD).
\end{abstract} Drawing from existing research on sacrifice within romantic relationships (e.g., Impett \& Gordon, 2008), this project examined whether non-Celiac partners' adherence to the GFD during shared mealtimes impacted relationship satisfaction for both couple members. Female Celiacs and their non-Celiac cohabitating partners ( $N=152$ couples) were recruited for an online survey through various support organizations. Given the dyadic design of this study, the Actor-Partner Interdependence Mediation Model (APIMeM; Ledermann, Macho, \& Kenny, 2011) was used to examine the mediating influence of Dietary Approach and Avoidance Motives. Results indicated that partner support in the form of shared GFD adherence bolstered couple happiness to the extent that it was performed for positive gains (e.g., promoting health and well-being) by the non-Celiac. While dietary sacrifice was positively associated with Celiacs' relationship satisfaction above and beyond non-Celiacs' endorsement of Dietary Avoidance Motives, both dyad members experienced significantly lower relationship satisfaction when non-Celiac partners adhered to the diet to deflect negative outcomes (e.g., rejection, fighting). This 
study serves as the first application of relationship sacrifice research to a specific health issue, and the first psychological exploration into intimate partners' dietary support processes within the Celiac population. 


\section{Dedication}

This manuscript is dedicated to my son, Samuel, whose arrival delayed the timeline for this project in the best way imaginable. 


\section{Acknowledgements}

I would like to thank my advisor, Cynthia Mohr, who has continually provided the guidance and encouragement needed to progress and define the scope of my work. I would like to thank my cohort and peers, whose mere presence and thoughtful insights have been a daily inspiration to me. I would like to thank my committee, whose valuable feedback helped to shape the parameters of my survey, and who challenged me to approach the underlying theories from new and interesting perspectives. I would like to thank the Celiac community, whose enthusiasm for this project helped tremendously during the recruitment process and inspired me to persevere throughout this journey. Finally, I would like to thank my dear husband, Christopher, who has been a pillar of strength, a constant source of support and inspiration, and a model for patience above and beyond what seemed humanly possible. Thank you all so very much. 
Table of Contents

Abstract

The Actor-Partner Interdependence Mediation Model .................................................30

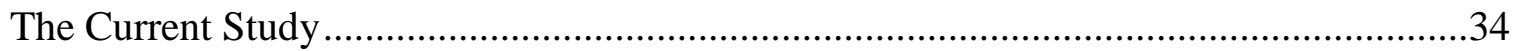

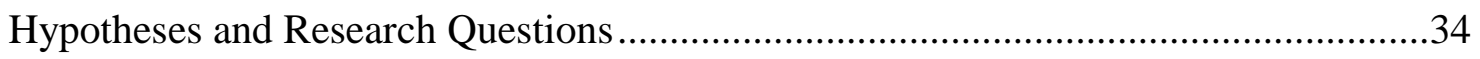

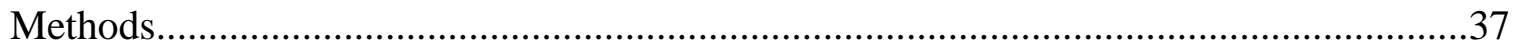

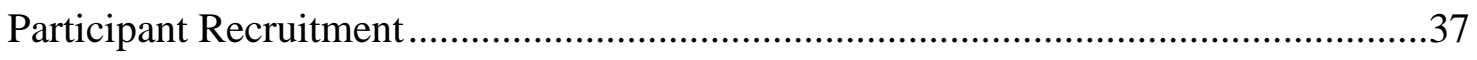

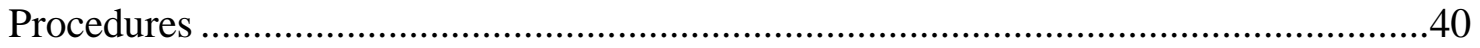

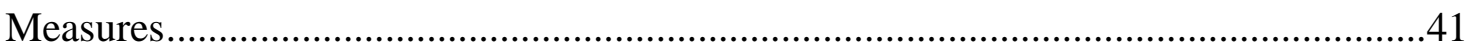

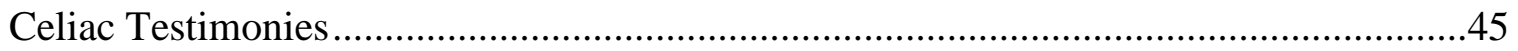

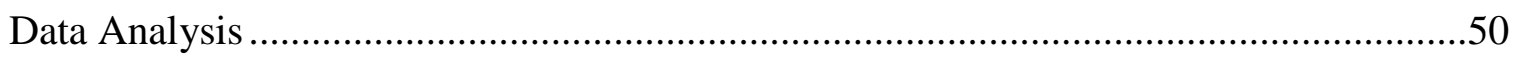

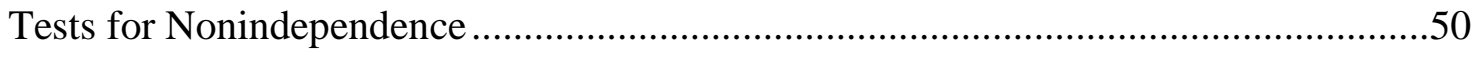

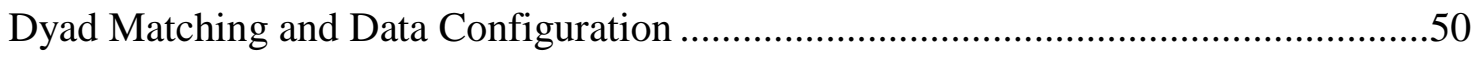

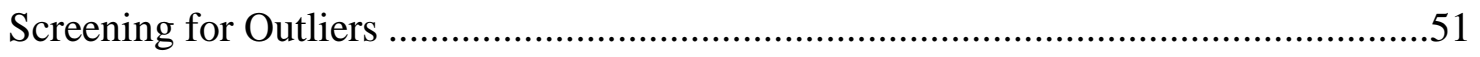

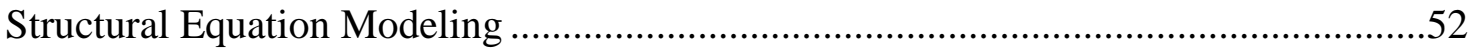

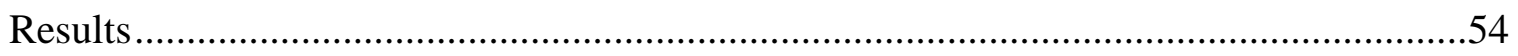

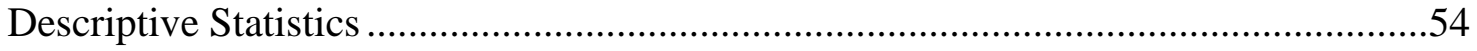

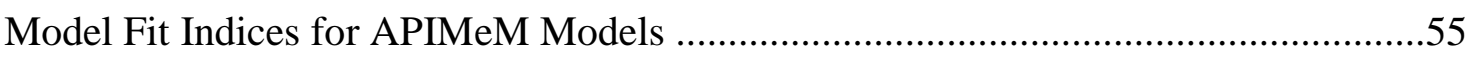

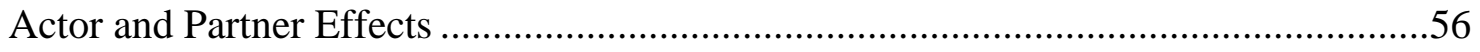

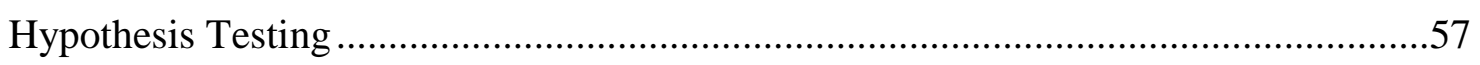

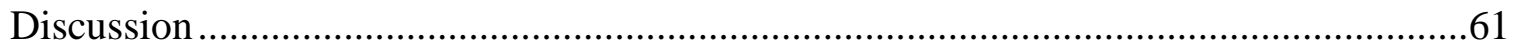

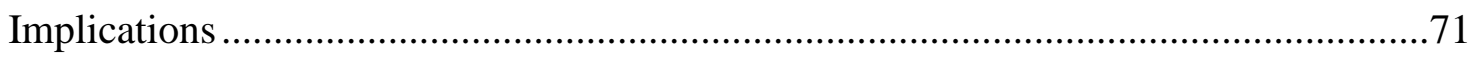

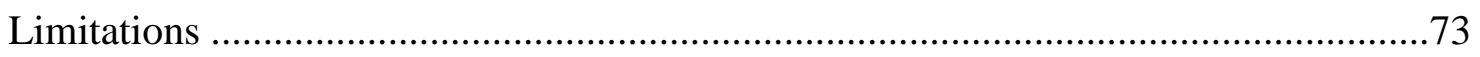

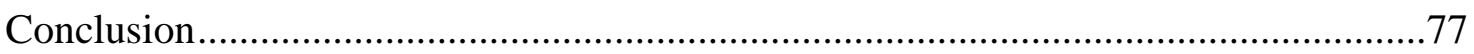




\section{Table of Contents (cont.)}

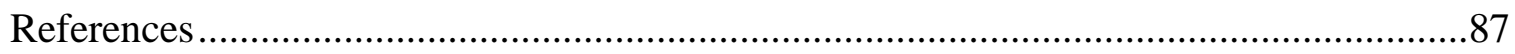

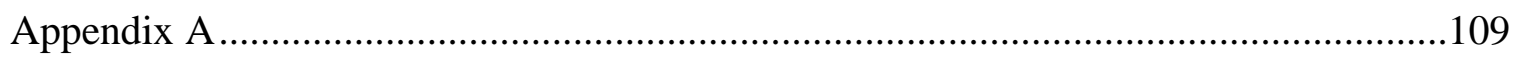

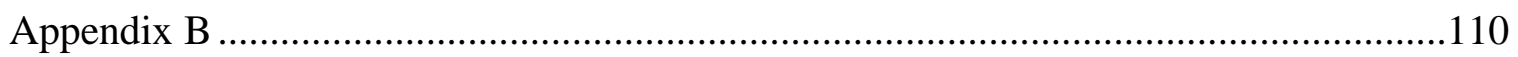

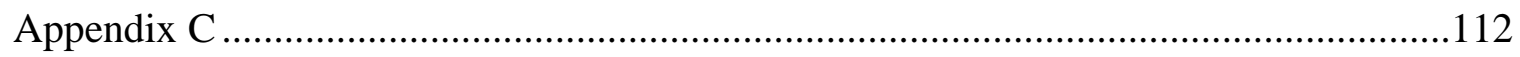

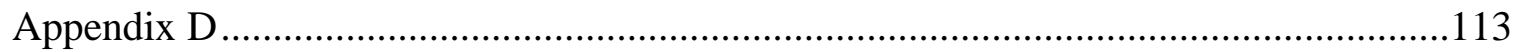

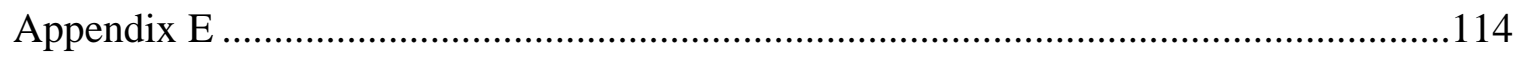


List of Tables

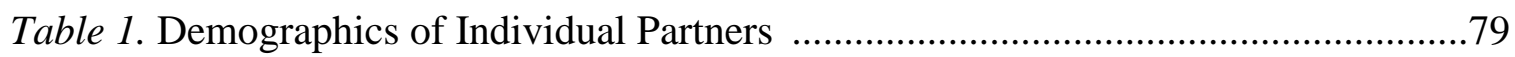

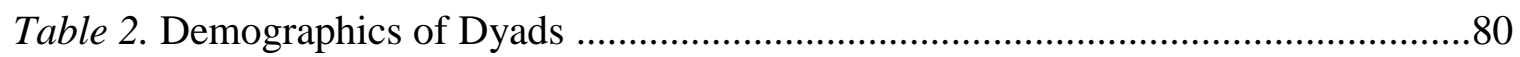

Table 3. Gluten-free Diet Adherence of Individual Partners ...........................................81

Table 4. Within-person Correlations for Celiac Partners ..............................................82

Table 5. Within-person Correlations for Non-Celiac Partners ........................................83

Table 6. Between-person Correlations Comparing Non-Celiac and Celiac Partners .......84

Table 7. Between-partner Descriptive Statistics, Correlations, and Pairwise t-tests ........85

Table 8. Parameter Estimates for Two Simplified Mediation Models ............................86 


\section{List of Figures}

Figure 1. Example of Fully Saturated APIMeM with Labeled Parameters ...................104

Figure 2. Saturated APIMeM with Dietary Approach Motives as the Mediator ...........105

Figure 3. Saturated APIMeM with Dietary Avoidance Motives as the Mediator ..........106

Figure 4. APIMeM with Dietary Approach Motives, Controlling for Depression ........107

Figure 5. APIMeM with Dietary Avoidance Motives, Controlling for Depression .......108 
Exploring Dietary Sacrifice in Intimate Relationships for Couples with Celiac Disease

Celiac Disease (CD) has emerged as a widespread public health concern, which currently affects at least three million Americans (Hornell, 2008). Although once considered scarce in the United States, studies show that the odds of developing Celiac are 1:39 for individuals who are genetically related to someone with CD and at least 1:133 for those who are not (e.g., Fasano et al., 2003; Green et al., 2001). Symptoms differ between individuals (Hornell, 2008), and can include both noticeable (e.g., bloating, skin rash, hair loss, gas, diarrhea) and silent characteristics (e.g., depression, headache, infertility, anemia, night-blindness; Copelton \& Valle, 2009). Untreated CD can result in multiple adverse health outcomes, such as certain types of cancer (Catassi, Bearzi, \& Holmes, 2005), osteoporosis, neuropathy, schizophrenia, liver disease, and Alzheimer's (Collin et al., 1994). The only known treatment for this autoimmune disorder is strict, life-long adherence to the gluten-free diet (GFD), which excludes all ingestible items containing ingredients derived from wheat, barley, and rye (Green, 2005). Seventy percent of patients report full recovery of symptoms as soon as two weeks from initiation of the diet (Farrell \& Kelly, 2002).

Multiple health studies have been performed to assess the link between GFD adherence and quality of life for people living with CD. Research suggests that maintaining the diet is associated with feelings of isolation, constant fear of gluten contamination, and concern for bothering others (Sverker, Hensing, \& Hallert, 2005). Both men and women with Celiac report feelings of distress associated with the cost of gluten-free (GF) food items, time spent preparing meals, and difficulty enjoying holidays 
(Sverker, Ostlund, Hallert, Hensing, 2009). Some have speculated that these experiences are attributable, in part, to societal norms pertaining to cooking behaviors. They posit that Celiac patients may experience lower well-being and increased illness-related distress to the extent that they are cooking separate meals for themselves and their families during shared mealtimes (Hallert et al., 1998; Hallert et al., 2002). As of yet, no empirical investigations have been performed to test this proposed association; however, it is posited here that one of the ways in which cooking separate meals may be particularly distressing for Celiac individuals in cohabitating intimate relationships is due to the fact that maintaining the GFD requires a divergence from couples' communal eating norms.

Generally speaking, the sharing of meals is a common and vital activity at every stage within the course of romantic relationships, and can serve to continually reinforce the bond between two partners (e.g., Bove, Sobal, \& Rauschenbach, 2003; Kemmer, Anderson, \& Marshall, 1998; Markey, Markey, \& Birch, 2001; Ristovski-Slijepcevic \& Chapman, 2005; Sobal \& Nelson, 2003). Having similar dietary preferences has been implicated as an important symbol of partners' like-mindedness and often serves as a catalyst for engaging in new relationships (e.g., Bove et al., 2003). In fact, one of the most common first-date activities is eating out at a restaurant together, the choosing of which carries substantial symbolic undertones that can aid in determining the fate of a potential budding romance (Amiraian \& Sobal, 2008). The subsequent courtship process involves a shift from consuming public meals to eating in more private dining settings, which is often accompanied by additional shared behaviors such as shopping for ingredients and cooking together (Rappoport, 2003). 
Nutrition researchers have often defined the processes of purchasing and preparing food items to be important household chores that set the tone for family meal interactions and dietary practices (e.g., Devine, Connors, Sobal, \& Bisogni, 2003; Nelson, Sapp, Berkman, Li, \& Sorensen, 2011). As such, cohabitation is where the true convergence of eating behaviors has been found to occur in relationships (e.g., Kemmer, Anderson, \& Marshall, 1998; Markey, Markey, \& Birch, 2001; Ristovski-Slijepcevic \& Chapman, 2005). In fact, cross-sectional studies conducted across multiple cultures have revealed that cohabitating partners and spouses display nearly the same behaviors in both nutrient intake and types of foods consumed (e.g., Louk, Schafer, Schafer, \& Keith, 1999; Patterson, Sallis, Nader, Kaplan, Rupp, Atkins, \& Senn, 1989), and that partners tend to reflect greater long-term food concordance than friends or siblings (Pachucki, Jacques, \& Christakis, 2011).

Evidence suggests that the majority of $\mathrm{CD}$ diagnoses for individuals in romantic relationships may occur after couples have already been living together for some time. Medically-confirmed Celiac individuals are generally diagnosed between the ages of 40 and 60 , and the average time between recognition of symptoms and diagnosis is 11 years (Green et al., 2001). Yet, within the American population, most adults tend to marry prior to the age of 30 and incidences of premarital cohabitation have continually risen over the past 25 years (Cohen \& Manning, 2010). Further, three-quarters of women who enter a cohabitating relationship go on to marry that partner (Lichter, Turner, \& Sassler, 2009). Thus, couples in which one member has CD have likely already established a history of communal eating norms prior to the Celiac diagnosis. The GFD subsequently forces one 
member of the relationship to deviate from the shared dieting practices, which introduces a new point of negotiation and compromise during food interactions between partners. The outcomes of such interactions have potentially substantial implications for both the dietary adherence of the Celiac patient as well as relationship satisfaction for both partners.

Previous research provides very little insight into the psychosocial mechanisms surrounding such deviations from couples' eating patterns. However, more importantly, no studies have as of yet explored the implications of a non-dieting partner voluntarily joining in the dietary changes of the other, which may be a valuable mechanism for maintaining or enhancing relationship satisfaction. Within the social psychological literature, such behavior is considered an act of sacrifice, which is defined as a positive coping process whereby an individual cedes their own interests for the sake of benefiting their significant other or the relationship (Impett \& Gordon, 2010). This behavior can be motivated by either the want to approach positive gains (e.g., optimizing the partners' health and well-being) or avoid negative outcomes (e.g., conflict surrounding meals; Impett, Gable, \& Peplau, 2005), and is thought by some researchers to be the ultimate representation of true love (Noller, 1996).

Rusbult and Van Lange (2003) noted in their review of interdependence-based studies that discordant interactions between partners wherein one then agrees to the conditions of the other produce symbolic outcomes. The compromising partner experiences positive affect toward themselves following a sacrificing act because they feel they have communicated their love, served as an agent of their partners' pleasure, 
and confirmed their belief that they are a caring person (Rusbult \& Van Lange, 2003). They also develop more positive affect toward their relationship, perceive greater intimacy, and report engaging in more shared activities (Impett \& Gordon, 2008). Additionally, Kelley (1979) has suggested that intimate partners are generally cognizant of when their significant other sacrifices his or her own interests for their benefit. Thus, the receiving partner experiences enhanced satisfaction toward the relationship due to the fact that perceiving their significant other's sacrifice bolsters their impression that their partner is caring, thoughtful, and trustworthy (Wieselquist, Rusbult, Foster, \& Agnew, 1999).

Within couples wherein one member has been diagnosed with $\mathrm{CD}$, food preference discordances during shared mealtimes may result in one of three outcomes: the non-Celiac complying with the GFD (i.e., sacrifice), each partner dining independently (e.g., frozen meals, eating out), or the patient 'cheating' on their prescribed diet. The third pathway would lead to negative physiological and psychological outcomes for the patient, which would likely also adversely affect their partner and cause distress in the relationship. Whereas, a dietary sacrifice made by the non-Celiac for the purpose of improving circumstances for the Celiac partner or relationship may produce positive outcomes; these may take the form of enhanced couple functioning and stricter dietary adherence for the patient. This study will directly investigate the implications of this particular scenario, as a means of both better understanding the role of relationships as they influence Celiac treatment adherence as well as furthering the literature on sacrifice 
in intimate relationships by applying the framework within the context of dieting behaviors.

\section{Study Overview}

Thus, the primary thesis driving the current investigation was that a partners' dietary sacrifice, or willingness to cede their own food preferences during shared mealtimes, would produce the same outcomes for relationship satisfaction that have been found in previous studies of sacrifice in intimate relationships (e.g., Van Lange, Rusbult, Drigotas, Arriaga, Witcher, \& Cox, 1997; Impett \& Gordon, 2008). Further, consistent with prior literature exploring the motivational processes underlying partners' willingness to sacrifice (e.g., Impett, Gable, \& Peplau, 2005; Impett, Gordon, Kogan, Oveis, Gable, \&Keltner, 2010), it was expected that participants' endorsement of Approach (e.g., increased intimacy, improved health) and Avoidance (e.g., avoiding conflict) motives would mediate the relationship between GFD adherence and relationship satisfaction. Specifically, it was proposed that satisfaction would be higher for partners who endorse Approach Motives and lower for those endorsing Avoidance Motives for dietary sacrifice. In order to account for nonindependence between members of participating couples, data were analyzed using the Actor-Partner Interdependence Mediation Model

(APIMeM; Ledermann, Macho, \& Kenny, 2011) which allowed for testing the effects of individuals' predictors and mediators on both their own outcomes (actor effects) as well as their significant others' outcomes (partner effects). The following literature review more thoroughly explores the role of Interdependence Theory and sacrifice as they relate 
to couple satisfaction. Further, current literature on shared eating behaviors and dietary adherence within intimate relationships is provided in detail.

This is the first psychological study to explore relationship processes as related to dietary adherence for individuals with $\mathrm{CD}$, and thus could greatly influence future intervention and empirical work within this unique population. As dietary sacrifice is directly relevant to both the maintenance of shared eating behaviors as well as the physical health of diet-related illness populations, it is an important and relevant distinction that warrants psychological investigation above and beyond general sacrifice. However, results of this study also yield clear implications for the general population, as dieting is extremely common in the United States (Markey, Markey, \& Birch, 2001) and strict long-term adherence to any one diet is rare (Anderson \& Gustafson, 1989). In fact, despite its inherent connection to $\mathrm{CD}$, the GFD is among those that have gained mass popularity over the past few years with sales of GF products projected to meet $\$ 5$ billion by 2015 (Haupt, 2012). Many individuals are voluntarily adopting dietary changes such as this in order to lose weight or maintain adequate health, as rates of diet-related illnesses are currently reaching epidemic proportions. For example, approximately 26 million Americans are diagnosed with Type II diabetes (CDC, 2011), obesity is projected to affect $44 \%$ of citizens by the year 2030 (Voelker, 2012), and incidences of cardiovascular disease and hypertension continue to increase exponentially (Andreyeva, Sturm, \& Ringel, 2004).

Given this information, it is clear that there are certainly situations within the span of many romantic relationships in which one member will suddenly change their diet, 
either by choice or out of necessity (e.g. allergies, intolerances, medical recommendations). Thus, better understanding such divergences is crucial in order to gain further insight into relationship coping processes and health behavior engagement. This study serves as the first empirical investigation into the implications of dietary sacrifice on couple satisfaction, as well as the first investigation of shared dieting behaviors within intimate relationships to be analyzed at the dyadic level. The findings produced serve to further literature on sacrifice, as this study will apply the framework to a specific health-related context within a distinct patient population.

\section{Intimate Relationships and Health}

Romantic relationships are important to consider when exploring correlates of and influences on individuals' physical and psychological health, as intimate partners are often the first consulted during times of stress and need (e.g., Beach, Martin, Blum, \& Roman, 1993; Cutrona, 1996). Persons in romantic relationships tend to display higher levels of happiness and life satisfaction, and report better health than those who are single (e.g., Gove, 1979; Tucker, Friedman, Wingard, \& Schwartz, 1996). Further, marriage tends to be associated with less physiological pain, greater cardiovascular functioning and subjective well-being, as well as enhanced longevity (e.g., Kiecolt-Glaser \& Newton, 2001; Markey, Markey, \& Gray, 2007; Tucker et al., 1996; Vitaliano et al., 1993). Spouses who report greater levels of partner support also display stronger relationship satisfaction than those with low levels (Pasch, Bradbury, \& Davila, 1997), and tend to reflect higher rates of medical treatment adherence (DiMatteo, 2004). There are multiple mechanisms by which couple members may influence each other's health and well-being; 
for instance, one partner may encourage positive health attitudes and behaviors in the other (e.g., Markey, Markey, Schneider, \& Brownlee, 2005), exert social control to regulate the others' engagement in adverse health practices or bolster engagement in prohealth behaviors (Butterfield \& Lewis, 2002; Umberson, 1992), or enhance the others' happiness which in turn leads to them to experience more positive health outcomes (Cohen, 1988).

Yet, relationships are complex and can also serve as one of the greatest sources of stress for individuals, especially when of poorer quality. Multiple researchers have noted that the deleterious effects of negative partner interactions may have more powerful influences on healthy functioning and relationship satisfaction than the benefits gained from positive interactions (e.g., Gottman, 1994; Diener \& Oishi, 2005; Schwarzer \& Leppin, 1991). Negative interpersonal conflict and lack of support within a union has been associated with engagement in adverse health behaviors (e.g., increased food consumption, heavy drinking; Umberson \& Montez, 2010) and poorer health outcomes (e.g., greater weight gain; Umberson, Williams, Powers, Liu, \& Needham, 2006; Umberson \& Montez, 2010). Relationship dissatisfaction is likewise related to decreased engagement in positive health behavior changes, greater occurrences of negative health issues, and increased mortality (e.g., Robles \& Kiecolt-Glaser, 2003).

However, it is often difficult to truly distinguish the direction of causality between relationship quality and health outcomes when sifting through these reported findings. Surprisingly, the majority of research in this area has been conducted at the level of the individual, which has produced primarily mixed results; indicating at times that 
perceptions of the quality of the relationship are a strong predictor of health outcomes regardless of behavior, while at other times finding that perceived partner influence on specific behaviors (e.g., increasing self-efficacy) is more highly associated with health and psychological well-being (Markey, Markey, \& Gray, 2007). There is a great need in current health-related psychological research to move toward dyadic, or couple-focused, methodology, in order to truly understand the interrelated nature of partners' behaviors and influences on each other (Lewis, McBride, Pollak, Puleo, Butterfield, \& Emmons, 2006).

\section{Interdependence Theory}

In fact, multiple relationships researchers have indicated that studies of couple processes should always be conducted at the dyadic level, to account for the inherent interdependence between partners' perceptions and behaviors (Revenson, Kayser, \& Bodenmann, 2005). Within the context of an intimate partnership, the health of one member tends to be strongly associated with the health of the other, indicating the presence of crossover effects between partners (Wilson, 2001). One of the primary assumptions in dyadic research is that responses between members of a relationship are characteristically nonindependent; meaning partners' scores will either be more similar or more different from each other due to the fact that the interacting individuals are psychologically connected to one another (Kenny, Kashy, \& Cook, 2006). Accounting for interdependence allows the researcher to better explore the mechanisms by which interacting partners influence each other's psychological, behavioral, and physiological outcomes (e.g., Kelley, 1979; Lewis et al., 2006; Thibaut \& Kelley, 1959). 
Interdependence Theory (IT) provides a basis from which much of the literature on dyadic processes has been built, and establishes a framework by which researchers can explore the meaning individuals attribute to interpersonal interactions as well as to what purpose they engage in social situations (Kelley, Bercheid, Christensen, Harvey, \& Huston, 1983; Kelley \& Thibaut, 1978). Within this theory the basic premise exists that partners act out certain behaviors during interactions based on their anticipation of either benefits for themselves or for their relationship. Thibaut and Kelley (1959) defined partner interactions as situations in which individuals "emit behavior in each other's presence, they create products for each other, or they communicate with each other" ( $\mathrm{p}$. 10). These interactions produce outcomes in the form of rewards and costs, which are more evident and predictable the longer a relationship is maintained (Rusbult \& Buunk, 1993). It is from these anticipated interaction consequences that global outcomes such as relationship satisfaction are born. However, Rusbult and Buunk (1993) note that most partners are not overly concerned with 'outcome counting', as it is generally understood that reciprocity will eventually equal out over time, placing less emphasis on the need for immediate benefits. This allows partners to feel willing to cede their own interests in a given situation for the good of their relationship.

To address the impetus for couples' likelihood to engage in communal, interdependent coping responses, IT posits that intimate partners experience a transformation of motivation wherein their individual orientation shifts from being primarily self-centered to more relationship- and health-focused (e.g., Lewis et al., 2006; Rusbult \& Van Lange, 1996). This transformation is achieved through both members' 
mutual ascription of an event as meaningful or significant for the relationship. However, in the original conceptualization of the theory, Kelley and Thibaut (1978) noted that one of the crucial aspects of the transformation process is that each member in the dyad must have an understanding of what the others' responses and potential outcomes will be in order to truly know how to respond themselves. For instance, within the context of couples' dieting behaviors this indicates that both members must have information regarding the requirements of dietary adherence and what the implications of adhering (or not adhering) may be for the health of their partner or quality of their relationship. In the case that poor dietary adherence is perceived to have potentially negative relationship outcomes (e.g., lowered well-being or satisfaction), the non-dieting partner may then choose to forego his or her own self-interests to promote the health of the other by sharing in their required diet regimen.

Thus, this transformative process is born out of couples' level of correspondence, or the agreement between partners' preferred interests and outcomes in a given situation (Ruppel \& Curran, 2012; Rusbult \& Buunk, 1993; Rusbult \& Van Lange, 2003). When partners' desires conflict, or are noncorrespondent, with one another their interaction is considered psychologically rich in that it inspires the initiation of benevolence-related cognitions and intrinsic cost-benefit analyses (e.g., Impett, Gable, \& Peplau, 2005; Rusbult \& Van Lange, 2003). The precedents and interpretations of such interactions can present themselves in multiple iterations. For instance, both partners may have similar motivational interests, which lead to joint actions in pursuit of benefits for only one partner. This may be the case in situations where one member of a relationship is living 
with CD. Both partners will act cooperatively in pursuit of the improved health status or treatment adherence of the patient; however, each member will likely be psychologically and/or physically affected by these joint coping efforts (Reed, Butler, \& Kenny, 2013). There are also situations in which both partners may hold divergent preferences yet be pursuing a desired shared outcome (e.g., relationship satisfaction) leading one or both to compromise their own interests for the benefit of achieving that favored result. For instance, when planning a romantic dinner, one partner may favor Mexican food while the other prefers Chinese; in order for both individuals to derive satisfaction from their relationship that evening one will most likely sacrifice their own gastronomic desires to accommodate those of the other (Impett \& Gordon, 2008).

\section{Sacrifice in Intimate Relationships}

Much of the research investigating sacrifice in intimate relationships has been based in IT and has capitalized on the transformation of motivation framework. The underlying assumption here is that sacrificing behaviors occur, in part, as a result of the interdependent nature of relationships. Paired individuals influence each other's attitudes, cognitions, and behaviors in a multitude of ways, daily and over the long-term (Kelley, 1979; Kelley \& Thibaut, 1978); and because each member of a couple has a stake in their relationship, and the affect and actions of one impact the other, there are benefits to be gained from making occasional compromises in order to enhance or maintain the status quo. Thus, sacrifice is defined as the motivation of an individual to forego immediate self-interest in order to promote the well-being of their partner or relationship (e.g., 
Impett, Gable, \& Peplau, 2005; Impett \& Gordon, 2008; Van Lange, Agnew, Harinck, \& Steemers, 1997).

Van Lange and colleagues were the first to begin exploring potential determinants and consequences of willingness to sacrifice in intimate relationships (Van Lange, Agnew, Harinck, et al., 1997; Van Lange, Rusbult, Drigotas, et al., 1997). In these early studies, participants were either provided a vignette to read and respond to with the likelihood that they would endorse a sacrificing behavior, or were asked to list the most important activities in their life and indicate their willingness to end the relationship if they had to give up one of those activities for their partner. Findings revealed that couples are generally more willing to forego their own interests to the extent that they feel strongly committed to their partner (Van Lange, Agnew, Harinck, et al., 1997; Van Lange, Rusbult, Drigotas, et al., 1997), are greatly invested in the relationship (Van Lange, Rusbult, Drigotas, et al., 1997), and perceive themselves to be lacking better alternatives (Van Lange, Agnew, Harinck, et al., 1997; Van Lange, Rusbult, Drigotas, et al., 1997). Further, willingness to sacrifice has been associated with higher levels of dyadic adjustment and relationship longevity (Van Lange, Rusbult, Drigotas, et al., 1997), as well as greater relationship satisfaction (Van Lange, Agnew, Harinck, et al., 1997; Van Lange, Rusbult, Drigotas, et al., 1997). This preliminary research aided in elucidating some of the psychological processes surrounding the implications of couple members' interdependence, as well as situations in which partners may cede their own interests in relationship scenarios. However, these original studies addressed only 
individuals' intentions to sacrifice, which is not necessarily indicative of their actual tendency to engage in sacrificing behaviors.

Conceptually, sacrifice is described as a behavioral response which can take on either a passive form, in which one member of a relationship forfeits a desirable intention (e.g., staying home with the spouse instead of going out with friends), or an active form, wherein one partner engages in behaviors that might otherwise be undesirable to them (e.g., spending more "bonding time" with the mother-in-law; Impett \& Gordon, 2008; Van Lange, Rusbult, Drigotas, et al., 1997). Both active and passive responses may occur simultaneously as well, as is likely often the case in situations of dietary sacrifice. Building on the earlier example, if the partner who prefers Chinese cuisine also finds Mexican food to be particularly unappealing, dietary sacrifice for them would mean both giving up their preferred meal and opting instead to eat the undesirable foods of their mate. Yet, it is important to note that although sacrifice may carry psychological or physical costs to the conceding partner, this concept refers only to the behavior itself, which is primarily enacted in the pursuit of positive, proactive goals (Van Lange, Agnew, Harinck, et al., 1997). In the case of a couple within which one member is medically required to adhere to the GFD, such a sacrifice by the non-Celiac partner may carry great psychological weight and could have significant implications for the patient and their overall relationship satisfaction. This may be differentially prevalent to the extent that the diet is perceived as being particularly difficult or unappealing by one or both members. More recent investigations have gone on to measure the actual occurrences of sacrifice behaviors in relationships. In a preliminary investigation, Impett and colleagues 
(2005) asked participants to list the types of sacrifice they generally committed for their partner. Responses represented a broad range of qualitative categories, including chorerelated (e.g., ironing the partner's clothes), appearance-related (e.g., wearing revealing clothing), and health-related (e.g., picked up or administered medicine) sacrifices, among others (e.g., family, friend, interaction). Similar to the results found in previous investigations of willingness to sacrifice, the daily frequency of sacrificing behaviors like those listed here has been positively associated with relationship satisfaction, albeit less so to the extent that a sacrifice is perceived as difficult for oneself or the partner (Mattingly \& Clark, 2012; Ruppel \& Curran, 2012). Further, individuals displaying greater communal strength, or willingness to sacrifice without contingencies, have been found to experience greater positive affect during sacrificing acts as well as heightened relationship satisfaction on the actual day of the sacrifice (Kogan, Impett, Oveis, Hui, Gordon, \& Keltner, 2010). In other words, frequent and easy sacrifices committed without anticipation of benefits to oneself may have a greater positive influence on relationship functioning than difficult sacrifices performed for less altruistic intentions.

Relationship Satisfaction. Interdependence theorists and sacrifice researchers have sought to define some of the mechanisms by which sacrificing behavior affects perceptions of relationship satisfaction for partners. Van Lange, Rusbult, Drigotas, and colleagues (1997) defined this outcome as "the level of dyadic adjustment and probability of a person persisting in a relationship" (p. 1375), and identified four distinct-yetinterrelated mechanisms through which sacrifice may serve positive benefits: 1) committing an act of sacrifice may encourage the recipient to reciprocate in future 
interactions; 2) sacrifice may ease a psychological, behavioral, or physiological burden faced by the recipient; 3) reliable and consistent acts of sacrifice within a relationship can reinforce a sense of trust and cooperation; and 4) sacrificing ones' own interests may serve to reinforce the belief in oneself as a caring individual who is strongly committed to his or her relationship. Kelley (1979) has suggested that intimate partners are generally cognizant of when their significant other cedes his or her own interests for their benefit, which bolsters their impression that the sacrificing partner is caring, thoughtful, and trustworthy (Wieselquist et al., 1999). Further, Rusbult and Van Lange (2003) noted that noncorrespondent interactions between partners wherein one chooses to sacrifice their own interests for the other produce symbolic outcomes; for the compromising partner, such an interaction reinforces a positive conceptualization of the self, due to the belief that by committing the sacrificing act they have effectively communicated their love, served as an agent of their partners' pleasure, and confirmed their belief that they are a caring person.

Approach-Avoidance Motivation. Yet, it is important to note that sacrifice does not always carry positive gains for the sacrificing partner, recipient, or relationship. For instance, when one partner is repeatedly making sacrifices for the other with no promise of reciprocity, they may experience reductions in happiness, self-esteem, and well-being, as well as increases in depression and anxiety (Fritz \& Helgeson, 1998). Such individuals generally perceive themselves as having a lack of power in their relationship (Kelley \& Thibaut, 1978), which leads them to overcompensate by repeatedly ceding their own interests to make their partners happy and maintain the bond (Impett \& Gordon, 2008; 
Impett \& Peplau, 2002). Another way in which sacrifice may be harmful to couples is through partners' endorsement of maladaptive motivations for engaging in such behaviors, such that if a partner is sacrificing for the purpose of avoiding arguments or placating the other both members may experience reduced relationship satisfaction. Impett, Gable, and Peplau (2005) were the first to investigate the distinct contributions of sacrifice motives to aid in explaining the differential outcomes of daily sacrificing behaviors within intimate relationships, as in why sacrifice can sometimes produce positive outcomes for a couple while at other times not. Specifically, they posited that the outcomes of a sacrifice behavior are determined by whether the action is motivated through a desire to gain positive benefits (Approach Motives) or avoid negative consequences (Avoidance Motives; Impett et al., 2005).

The use of these particular distinctions was, in part, originally inspired by Gray's (1987) neuropsychological model of motivation, which outlined the behavioral approach system (BAS) and behavioral inhibition system (BIS); the BAS motivates behavior based on rewards, while the BIS functions in response to punishments. Investigations into the relationship of these motivational systems to emotions and health have revealed that individuals high in BAS sensitivity report greater daily positive affect, life optimism, and subjective well-being as compared to those low in BAS. Conversely, those high in BIS sensitivity experience greater daily negative affect and increased physiological symptom reports (e.g., Coats, Janoff-Bulman, \& Alpert, 1996; Elliot \& Sheldon, 1997; Gable, Reis, and Elliot, 2000). On the basis of these findings, Gable (2006) conducted a series of three short-term longitudinal studies to investigate the utility of such Approach and Avoidance 
Motives in predicting differential social outcomes. Results indicated that participants' endorsement of approach social motives was predictive of positive social experiences such as reduced loneliness and increased satisfaction with social bonds, whereas avoidance social motives were linked with negative social experiences (i.e., increased loneliness, negative social attitudes, and relationship insecurity).

Impett and colleagues (2005) built upon Gable's work by applying the ApproachAvoidance framework to the study of sacrifice specifically within the context of intimate relationships, and measured the constructs from a state rather than trait-based perspective. Findings revealed that intimate partners who endorsed Approach Motives on a given day experienced more positive emotion, greater satisfaction with life, and higher relationship satisfaction; whereas individuals who endorsed Avoidance Motives experienced more negative emotions, reduced relationship satisfaction, and greater occurrence of conflict with their partner. Further, those who consistently sacrificed to approach positive gains displayed greater relationship longevity than those regularly endorsing Avoidance Motives. Findings also revealed that when controlling for Approach and Avoidance Motives no form of sacrifice was significantly related to relationship satisfaction, supporting the inclusion of motives in determining causal inference between specific sacrificing behaviors and couple well-being.

Of particular relevance to the current study, Impett and colleagues have recently begun to focus their work on more specific forms of sacrifice, in this case sexual sacrifice between partners. In the first investigation, Impett, Peplau, and Gable (2005) found that daily sexual sacrifices engaged in through Approach Motives were predictive of greater 
feelings of relationship satisfaction, as compared to daily avoidance motivated sexual sacrifices. Similarly, Impett, Stachman, Finkel, and Gable (2008) found that approach relationship goals buffered against declines in sexual desire over time, as well as heightened sexual desire during daily sexual encounters. Further, approach sexual goals were found to mediate the relationship between approach relationship goals and sexual desire, such that those higher in approach relationship goals and approach sexual goals experienced greater desire toward their partner. The outcomes of these more tailored investigations provide legitimacy to the idea of moving away from general, open-ended conceptualizations of sacrifice and encourage the further study of this phenomenon within more specific contexts. Further, each of these investigations has revealed strong associations between motives for sacrifice and relationship outcomes (e.g., couple satisfaction and longevity), indicating that there is great benefit in considering Approach and Avoidance Motives as a potential mediators to explain associations between couples' health-related sacrificing behaviors and enhanced relationship well-being.

\section{Dietary Processes in Relationships}

Making food choices within a family setting is a complex process, in which each member's preferences must be considered (Brown \& Miller, 2002). Studies of eating behaviors focusing within intimate relationships have shown that the convergence of dietary practices for some occurs even before the point of marriage. If the couple has been cohabitating, this phenomenon has likely been triggered through the simple acts of shopping for groceries and cooking together (e.g., Kemmer, Anderson, \& Marshall, 1998; Markey, Markey, \& Birch, 2001; Ristovski-Slijepcevic \& Chapman, 2005). As such, 
studies conducted in multiple countries reveal that live-in romantic partners typically display the same or similar habits in both nutrient intake and types of foods consumed (e.g., Louk, Schafer, Schafer, \& Keith, 1999; Patterson, Sallis, Nader, Kaplan, Rupp, Atkins, \& Senn, 1989).

Although no studies have, as of yet, empirically investigated the role of dietary sacrifice within romantic relationships, preliminary investigations of couples' shared dieting behaviors have provided a framework from which to begin sculpting and defining this phenomenon. For instance, Kemmer, Anderson, and Marshall (1998) conducted interviews with 22 couples in the United Kingdom three months before and after they were married. They found that, regardless of gender, the majority of romantic partners valued and made a strong effort to eat the same meal together with their spouse each evening, and many reported sharing the same food preferences. Those who did not directly share the same tastes made an effort to compromise their desires in order to please their partner. In fact, most noted that cooking meals to match their partners' preferences was considered a fun, enjoyable activity that heightened the overall value of the meal. Similar studies have been conducted in Australia (Craig \& Truswell, 1988/1994) and in America (Bove et al., 2003), and have produced the same fundamental results. Within couples, partners place strong value on eating together and consistently indicate positive implications of this practice for their overall relationship quality.

Bove and colleagues (2003) expanded on this concept by exploring both the consensus and conflict surrounding meals in new marital relationships. They defined food conflicts as incompatible cognitions, wants, and/or behaviors between two partners 
regarding food choices. The researchers conducted interviews separately with both members of 20 heterosexual couples at the point at which they entered marriage and one year after. They found that while most partners did report similar tastes, there were some who indicated they had hidden their dietary preferences while dating to create a false impression of food compatibility and others who revealed their dissimilarities early in the relationship as an opportunity to gain acceptance and respect. Though, despite differences in food habits at the point of cohabitation most couples merged their dietary behaviors as time progressed, with convergent eating patterns being nearly universal across participating couples at the second time point. The partners who did report a change in eating behaviors from similar to divergent between the two time points considered food to be the primary source of conflict in their lives, and reported that most of these disagreements revolved around health and body weight concerns. These findings not only emphasize the importance placed on shared eating behaviors within intimate relationships, but also the struggles encountered by couples within which one partner engages in divergent dietary practices.

The few studies that have investigated dietary behaviors within established cohabitating couples have elucidated the complexities surrounding partners' processes in compromising their food decisions, and have begun to examine the reciprocal impacts on relationship satisfaction and dietary adherence. Trief and colleagues (2003) conducted interviews with 40 diabetes patients and 32 spouses of diabetics and found that the most helpful forms of support for diabetes self-management revolved around dietary control; specifically, participants reported that help with grocery shopping and food preparation 
and maintaining shared diets were the most beneficial support behaviors contributing to treatment adherence and couple well-being. Paisley, Beanlands, Goldman, Evers, and Chappel (2008) conducted semi-structured interviews with 21 couples to investigate the emotional repercussions of an individual's dietary change on themselves and their partner within a general diet-related illness sample (e.g., hypertension, diabetes, cancer, and hypoglycemia). They found that the significant others who adhered, at least sometimes, to the dieters' requirements reported feeling strong desire to support the dieter and a sense of closeness in the relationship, yet some also indicated feelings of skepticism, anger, and disengagement. Similarly, Ryden and Sydner (2011) conducted interviews with 26 individuals in Sweden to investigate the role of social relationships in maintaining the Mediterranean diet and found that relationships within the household had the strongest impact on dietary adherence, more so than coworkers or friends, and that the dieters' spouses played an important role in helping the dieter maintain adherence. Additionally the dieters whose partners shared in their diet reported greater relationship satisfaction than those whose partners maintained separate eating habits.

The only empirical study thus far to directly investigate relationship outcomes associated with shared dieting behaviors has been conducted by Franks and colleagues (2012), and focused exclusively within the diabetes population. The authors noted that the support associated with sharing the same meals is highly beneficial for diabetics' dietary adherence and can serve to greatly reduce illness-associated distress. However, they also warned that spouses' unwillingness to accommodate patients' dietary requirements in their daily routines may be related to heightened emotional distress for 
both members of a couple. Correlation-based analyses were used to test the proposed hypotheses within a sample of 55 couples wherein only one partner had a formal diagnosis of diabetes. Results revealed that, controlling for marital satisfaction and diet adherence, the frequent sharing of meals was associated with less diabetes distress for patients. Further, spouses' marital satisfaction was inversely related to their own diabetes distress, as was spouses' diet-related support (e.g., meal sharing). It is important to note, though, that the results of this study are limited by the fact that the analyses were not performed on the couples as dyads, but rather were conducted as correlations based on husbands and wives as separate entities. As such, it is difficult to truly understand the interdependent, within-couple processes taking place in these proposed associations, including whether the romantic partners were sharing the same dieting behaviors.

Clearly, researchers have only just begun exploring the dynamic relationship processes involved in shared eating behaviors and dietary adherence. Current findings indicate that communal eating, or shared eating behaviors, may be an important component of relationship satisfaction for both members of a couple; however, the only empirical study thus far to include communal eating as a variable (Franks et al., 2012) looked only at the frequency with which couples ate together, not whether they were eating the same foods during those meals. This may help explain the weak association found in this study between shared meals and marital satisfaction, as some researchers posit that chronic disease patients experience worse quality of life outcomes to the extent that they have to cook one type of food for themselves and a separate type for their families during mealtimes (Hallert et al., 1998; Hallert et al., 2002). Little is known 
regarding the motivational processes driving one intimate partner to voluntarily

participate in the required diet of the other or what effect this form of sacrifice has on the perceived quality of the relationship. This phenomenon may be of particular relevance for intimate partners diagnosed with Celiac, who are medically required to deviate from their typical diet to engage in a strict GF regimen.

\section{Celiac and the Gluten-free Diet}

Celiac Disease (CD) is an autoimmune disorder for which symptoms are triggered by the ingestion of gluten - a protein found in certain grains such as wheat, barley, and rye. Although it was once characterized by symptomology related solely to gastrointestinal functioning, this illness is now recognized as being multisystemic in individuals who are genetically predisposed (Niewinski, 2008). For those with Celiac, gluten consumption causes severe damage to the mucosal villi of the small intestine, which inhibits the absorption of vital nutrients (Green, 2005). Thus, malnutrition is strongly associated with CD and is thought to be the cause of multiple symptoms associated with the disorder, including short stature (Alaedini \& Green, 2005), fatigue (Frissora \& Koch, 2005), delayed puberty (Farrel \& Kelly, 2002), peripheral neuropathy (i.e., tingling and numbness in extremities; Farrell \& Kelly, 2002), and iron-deficiency anemia (Alaedini \& Green, 2005). In total, there are at least 22 identified symptoms of $\mathrm{CD}$, which range from gastrointestinal (e.g., diarrhea, bloating, gas) to neurological (e.g., cerebellar ataxia, headache, dementia, epilepsy) and psychological (e.g., depression, anxiety; Bushara, 2005) in nature. The only known treatment for CD is strict, life-long adherence to the gluten-free diet (GFD), and seventy percent of patients report full 
recovery of symptoms as soon as two weeks from initiation (Farrell \& Kelly, 2002). Thus, dietary vigilance and fidelity is extremely important for this patient population.

Population Characteristics. In 2003, a large multicenter study was conducted to gain a better understanding of the demography and epidemiology of CD in the United States (Fasano et al.). Over 13,000 participants representing 32 states who were either at risk $(n=9,019)$ or not at risk $(n=4,126)$ for developing $C D$ (based on genetic risk factors) were recruited. Subjects were $57 \%$ female and nearly evenly distributed across age groups, which ranged from zero to over 60. Seven milliliters of blood was drawn from each participant, and the presence of the IgA EMA and IgG AGA antibodies were measured. Endoscopic biopsy of the intestine was performed for participants who were either EMA positive or IgG AGA positive and IgA deficient, and biopsy specimens were blindly evaluated by two independent experts. Results of this study suggested that the prevalence of $\mathrm{CD}$ in the United States ranges from $4.54 \%$ among first-degree relatives of patients to $.75 \%$ for not-at-risk subjects, regardless of the presence of symptoms, and affects $1 \%$ of the population overall (95\% CI: .05-1.26\%); $97 \%$ of confirmed Celiacs were White; and women with Celiac outnumbered men nearly 3:1 (see also Green et al., 2001).

Internationally, $\mathrm{CD}$ rates are shown to be highest in countries for which wheat and wheat products are the most highly consumed foods (Europe, the Middle East, South America, Asia, and North Africa), and the rate of incidence worldwide is estimated at $1 \%$ (Green \& Cellier, 2007). Interestingly, the greatest prevalence of this autoimmune disease has been reported in a North African refugee population, although it is rarely diagnosed 
in African Americans, Hispanics, or Asians in North America (Green, 2005). The reason for the proposed under-diagnosis and lack of recognition of $\mathrm{CD}$ in non-White ethnic groups has yet to be explained in the literature, though researchers warn against attributing the illness to any one racial group. In studies seeking to confirm or explore Celiac diagnoses in which the researcher noted the race/ethnicity of the subjects, the diagnosed population typically reflects primarily non-Hispanic Whites (all >84\%; Hoffenberg et al., 2003; Lebwohl, Tennyson, Holub, Lieberman, Neugut, \& Green, 2012; Not et.al., 1998). Lebwohl and colleagues (2012) confirmed in their study of racial disparities in duodenal biopsy administration for CD that only two prior studies had included African American participants; and, in their own study, noted that this population is significantly less likely to receive biopsy than non-Hispanic Whites. Thus, though the current project did not screen based on diagnosis type nor racial distinction, it was expected based on the literature that the recruited participants would be primarily White and female.

Celiac Relationships. Currently, there are no studies that have investigated intimate relationships within the context of CD. In fact, the vast majority of Celiac articles published across disciplines fail to even mention or account for marital status. Most of the literature on psychological implications and behavioral antecedents of GFD adherence has been born out of health and nutrition research. Results of these studies primarily indicate extreme difficulties maintaining dietary fidelity due to multiple practical and psychological explanations. For example, Ciacci and colleagues (2003) found that, although $97 \%$ of their patient sample $(N=581)$ showed a strong understanding 
of CD and the GFD requirements, only $74 \%$ reported strict adherence. Some of the listed reasons for transgressing included problems ordering in restaurants, feelings of anger toward CD, a desire to not be different from others, and hope that small amounts of gluten would not be harmful. Fifteen percent of participants "often" or "very often" felt embarrassed by having to ask for GF food at restaurants or parties. Similarly, Zardakas and colleagues (2006) conducted a study to evaluate the impact of the GFD on biopsyconfirmed Celiac patients, and found that $53 \%$ of participants $(N=5,240)$ brought GF foods with them 'all of the time' when traveling, $48 \%$ avoided restaurants 'some of the time,' and a majority of participants (53\%-67\%) indicated experiencing difficulties in locating GF products.

The few studies that have hinted at implications regarding the role of intimate relationships in coping with the GFD have found that living alone is associated with a reduced risk of developing anxiety disorder as compared to patients living in partnerships (Hauser, Janke, Klump, Gregor, \& Hinz, 2010), but that married couples display greater adherence than single individuals (Leffler et al., 2007). In other words, while maintaining the GFD may be less stressful when the patient has only their own eating habits to consider, the presence of the spouse could actually encourage stricter adherence overall. Further, Sverker and colleagues (2009) conducted a promising study to investigate the impact of CD on quality of life, which included testimonies from close male and female relatives in order to compare and contrast daily perceptions of stress associated with the diet. Unfortunately, the term "close" was not operationally defined, so it is difficult to infer whether these were intimate partners, parents, siblings, or otherwise. Regardless, 
results indicated that females with $\mathrm{CD}$ and male close relatives experienced the same stressor perceptions when it came to cost of food items, time (e.g., extra time spent preparing meals), tiresome comments from others when eating out, and difficulty traveling and/or enjoying holidays. Women with Celiac and male close relatives were also less inclined to engage in meals with others, in order to avoid feelings of social stigma and ostracism. Additionally, both men and women with CD reported feeling shame as a result of dilemmas associated with GFD adherence, and experienced similar levels of chronic anxiety associated with gluten contamination and dinner party invitations (i.e., considering the potential for gluten-free options, and declining participation).

It is therefore posited that individuals in the Celiac population attempting to maintain the GFD may benefit greatly from the dietary sacrifices of their partner. Sharing the same diet may limit patients' need to be overly vigilant of cross-contamination concerns, reduce potential stress from cooking separate meals for themselves and their family, save costs associated with purchasing individualized groceries, and possibly reduce some of the negative effects of dietary stigma. Patients' partners would also benefit from sharing the GFD, as this would likely reduce psychological and physical distress of the patient, which would also serve to ease the distress of the partner. As such, both members of the relationship would be working together to achieve a common goal of improving the patients' health and well-being, which is consistent with the definition posed for sacrifice (e.g., Van Lange, Agnew, Harinck, et al., 1997). In the case that the partner is sacrificing their dietary preferences through Approach Motives, these shared 
dieting behaviors may bolster couple satisfaction for both members of the relationship (e.g., Impett \& Gordon, 2008).

\section{The Actor-Partner Interdependence Mediation Model}

In order to test the following proposed hypotheses, couples' data were analyzed at the level of the dyad using a statistical model that has been specifically designed to account for interdependence between relationship partners. Despite the fact that studies of sacrifice in relationships have been conducted primarily from an IT perspective, specific analytical procedures for testing aspects of the theory have not yet been explicitly described. As such, analyses of interdependence have been inconsistent throughout the literature. Wickham and Knee (2012) recently identified this issue and explicated the utility of the Actor-Partner Interdependence Model (APIM) for testing hypotheses in terms of the concepts outlined in IT, describing it as the most widely accepted method for analyzing dyadic data.

The APIM was originally created to address the correlated, non-independent nature of couple members' behaviors and emotions (Kenny \& Cook, 1999). The design accounts for how individuals' responses predict their own actions (actor effects) as well as their romantic partners' actions (partner effects). Partners' scores are reciprocal, meaning that both members of the dyad have indicated responses on all of the same variables. Further, the model establishes controls for actor effects when measuring partner effects and vice versa, which is beneficial above and beyond the information obtained in more common correlation analyses (Kashy \& Kenny, 1999; Kenny \& Cook, 1999). In order to account for the inherent interdependence between partners' scores on a 
given construct, the model allows for correlation between individuals' predictor variables, as well as the unexplained variances in their outcome variables.

The APIM has been implemented on multiple occasions to investigate various predictors of relationship satisfaction (e.g., Barelds \& Barelds-Dijkstra, 2010; Molero, Shaver, Ferrer, Cuadrado, \& Alonso-Arbiol, 2011; Rowe, Doss, Hsueh, Libet, \& Mitchell, 2011), yet has never been used to directly explore eating behaviors within intimate partnerships. However, a limited amount of research has applied this model to the study of diet-related phenomena. For example, Markey and Markey (2010) recently conducted a study to address whether individuals' and partners' weight statuses (i.e., Body Mass Index) would predict the presence of weight concerns. The authors found that, at the level of actor effects, individuals' own weight status was significantly positively correlated to their weight concerns (i.e., higher BMI scores were associated with more concern); and analysis of the partner effects indicated that couple members' weight status was significantly negatively associated with their intimate partners' weight concerns. The implementation of the APIM in this example allowed the researchers to test the within-couple influences of each member's predictor variables on each other's outcomes while simultaneously controlling for all other effects, thereby accounting for the inherent interdependence between partners' BMI scores and the variance in their weight concerns.

In the current study, it was expected that each couple members' level of adherence to the Celiac partners' required GFD would relate to both their own relationship satisfaction (actor effect) as well as their partners' (partner effect). Of 
particular interest was the non-Celiacs' diet fidelity during shared mealtimes, as that served as the operational definition for dietary sacrifice. By ceding their own food preferences to join the GFD regimen of the Celiac partner it was expected that nonCeliacs would experience enhanced satisfaction, as committing the sacrificing act would bolster their impression that they are strongly committed to the relationship and that they are agents of their partners' love and well-being (Van Lange, Rusbult, Drigotas, and colleagues, 1997). Additionally, perceiving the non-Celiacs' adherence to the GFD was predicted to increase the Celaics' satisfaction in that it might build a sense of trust and cooperation in the relationship, as well as ease some of the psychological and physiological burden associated with the illness (Kelley, 1979; Van Lange, Rusbult, Drigotas, and colleagues, 1997; Wieselquist et al., 1999). These anticipated associations have also been supported by participants' testimonies during the previously reviewed interviews regarding the importance placed on shared eating practices (e.g., Bove et al., 2003; Kemmer et al., 1998; Paisley et al., 2008).

However, the pathways described do not necessarily address the full scope of what may be taking place in this proposed APIM model, as it is possible that the influence of an individuals' GFD adherence on their own and their partners' relationship satisfaction may depend upon their endorsement of a third variable (i.e., motive for sacrifice). Researchers have recently begun expanding the original APIM model to include such additional pathways (e.g., Debrot, Cook, Perrez, \& Horn, 2012; Ledermann, Macho, \& Kenny, 2011; Shröder-Abé \& Shütz, 2011). This new iteration has been designated the Actor-Partner Interdependence Mediation Model (APIMeM; Ledermann, 
Macho, \& Kenny, 2011). Mediation is a term used to define the statistical process wherein a predictor variable $(\mathrm{X})$ influences an outcome $(\mathrm{Y})$ through a third variable $(\mathrm{M}$; Baron \& Kenny, 1986). The inclusion of mediation into the traditional APIM involves the addition of two measured mediation variables $\left(M_{1}\right.$ and $\left.M_{2}\right)$ each with their own associated error terms, the variance between which is analyzed as a covariate. This creates, in total, 27 free parameters in a saturated APIMeM model for distinguishable pairs, which in this study are defined as dyads including one patient (Celiac) and one non-Celiac (romantic partner). Much of the literature on sacrifice has indicated that changes to relationship satisfaction are the result of not only the sacrificing act itself, but operate through partners' endorsement of Approach or Avoidance Motives (e.g., Impett, Gable, \& Peplau, 2005; Impett \& Gordon, 2008). As such, in order to truly understand the association between dietary sacrifice and satisfaction it was important to consider the extent to which the non-Celiac performed the dietary sacrifice based on a desire to improve the health and well-being of or avoid conflict with the Celiac partner. The APIMeM allowed for the inclusion of Dietary Approach and Avoidance Motives as mediators, and the testing of their effects on both the Celiac and non-Celiac partners' outcome. 


\section{The Current Study}

Thus, the purpose of this study was to apply the framework of sacrifice in intimate relationships within the context of Celiac couples' dieting behaviors and through the lens of Interdependence Theory. Following the Approach-Avoidance motivation findings put forth by Impett and colleagues (Impett, Gable, \& Peplau, 2005; Impett \& Gordon, 2008; Impett, Gordon, Kogan, Oveis, Gable, \& Keltner, 2010), Dietary Approach and Avoidance Motives for sacrifice were included as mediators to test the effects of dietary sacrifice - defined as voluntary Adherence by the non-Celiac partner during shared mealtimes - on Relationship Satisfaction. The pertinent pathways were examined using the APIMeM (see Figure 1 for an example with labeled parameters; Ledermann, Macho, \& Kenny, 2011), which allowed for the testing of mediations between members of a dyad while simultaneously controlling for all other pathways and accounting for interdependence between partners. Based on the sacrifice literature and previous qualitative research on communal eating in couples, this study tested relationships between non-Celiacs' GFD Adherence and both members' Relationship Satisfaction through their independent endorsements of Dietary Approach and Avoidance Motives for sacrifice.

\section{Hypotheses and Research Questions}

In the following hypotheses and research questions, mediations are signified based on whether the pathways of interest include actor or partner effects, and whether they refer to the Celiac (e.g., A1, P1) or non-Celiac (e.g., A2, P2). For instance, an Actor- 
Actor mediation for the dieting participant is described by $a_{\mathrm{A} 1} \rightarrow b_{\mathrm{A} 1}$; whereas an ActorPartner mediation for the non-Celiac is denoted as $a_{\mathrm{A} 2} \rightarrow b_{\mathrm{P} 1}$.

Hypothesis 1 (Actor Effect): Based on previous research indicating that couples primarily engage in shared dieting behaviors, and qualitative findings suggesting a positive influence of shared dieting behavior on Relationship Satisfaction, it was predicted that there would be a positive and significant actor effect for participants' dietary Adherence on their own Relationship Satisfaction (paths $c^{\prime}{ }_{1}$ and $c^{\prime}{ }_{\text {A2). }}$.

Hypothesis 2 (Partner Effect): Based on the proposed concept of dietary sacrifice, it was predicted that there would be a positive and significant partner effect for significant others' voluntary diet Adherence on Celiacs' Relationship Satisfaction (path $\left.c_{\mathrm{P} 1}^{\prime}\right)$. Specifically, Celiacs whose partners report higher levels of Adherence would experience greater levels of Relationship Satisfaction.

Research Question 1: Does a significant partner effect exist between Celiacs' Adherence and non-Celiacs' Relationship Satisfaction (path $\left.c^{\prime} \mathrm{P} 2\right)$ ?

Hypothesis 3 (Actor-Actor Mediation): It was expected that dietary sacrifice by the non-Celiac would be associated with reduced Relationship Satisfaction for himself or herself when mediated by his or her own endorsement of Avoidance Motives (Figure 3) and heightened Satisfaction when mediated by Approach Motives for sacrifice (Figure 2; path $\left.a_{\mathrm{A} 1} \rightarrow b_{\mathrm{A} 1}\right)$. Specifically, it was predicted that partners who typically commit dietary sacrifice (i.e., GFD Adherence) for the good of their relationships would report stronger levels of Relationship Satisfaction, whereas those committing sacrifice to avoid negative consequences would experience reduced levels. 
Hypothesis 4 (Partner-Actor Mediation): It was predicted that the influence of a non-Celiacs' voluntary Adherence on Celiacs' Relationship Satisfaction would be mediated by the Celiacs' own endorsement of Approach Motives (Figure 2; path $\left.a_{\mathrm{P} 1} \rightarrow b_{\mathrm{A} 1}\right)$. For example, the sacrifice of non-Celiacs' dietary preferences would be perceived by Celiacs, triggering the desire to reciprocate those intentions to achieve positive outcomes in their relationship, leading to greater feelings of Satisfaction.

Hypothesis 5 (Actor-Partner Mediation): It was predicted that Celiacs' Relationship Satisfaction would be related to non-Celiacs' dietary sacrifice positively through the partners' endorsement of Approach (Figure 2) and negatively through Avoidance Motives (Figure 3; path $a_{\mathrm{A} 2} \rightarrow b_{\mathrm{P} 1}$ ). For example, if the partner primarily commits dietary sacrifice to avoid negative relationship outcomes, the Celiac would report lower Relationship Satisfaction. Conversely, if the non-Celiac commits sacrifice to approach positive gains for the couple, the Celiac would experience higher Satisfaction. 


\section{Methods}

\section{Participant Recruitment}

Cohabitating and married couples in which only one member has CD were recruited via an online advertisement (see Appendix B) circulated through various Celiac support organizations and interested members. Specifically, the ad was posted on the Facebook and Twitter pages of the Celiac Disease Foundation (CDF), the National Foundation for Celiac Awareness (NFCA), the University of Chicago Celiac Disease Center, the National Celiac Disease Society (NCDS), and "Gluten Free Living” Magazine; and was subsequently "shared" by 199 Facebook and 47 Twitter subscribers. The ads distributed by the CDF and the NFCA received the highest number of Facebook “shares" (60 and 97, respectively). Recruitment took place over a period of nearly four months (April 14, 2014 through August 1, 2014) during the summer, thus avoiding any potentially confounding influences associated with food-relevant holidays.

Eligibility requirements were that partners be at or older than 18 years of age, in a committed relationship of at least six months, and diagnosed or have a partner with a diagnosis of CD. There were 516 female and 37 male Celiacs who submitted complete surveys; 490 were married or cohabitating (93\% female). Fifty-one percent of these participants had partners who also fully completed the survey. The sample was further restricted to only those which contained one Celiac and one non-Celiac member. Thus, the original dyadic sample consisted of 212 cohabitating couples $(87.7 \%$ female; $71 \%$ married; $92 \%$ heterosexual). The average time between when the first partner completed the survey and the second partner initiated theirs was one week ( $M_{\text {Days }}=7.03, S D=10.47$, 
$\left.M d n_{\text {Days }}=2\right)$. Regarding point of origin for couple recruitment, 84 were recruited through the CDF, 57 through the NFCA, 41 through the NCDS, 18 through the University of Chicago Celiac Disease Center, and 12 through “Gluten Free Living” Magazine.

Women with Celiac outnumber men three to one (Green, 2005), thus it was not surprising to find that the Celiac participants recruited for use in this study were primarily female $(87.7 \%)$. Previous CD findings have revealed significant gender differences between patients on measures of well-being and health-related quality of life such that females tend to experience lower levels than males (e.g., Hallert et al., 1998; Hallert et al., 2002; Zardakas et al., 2006). Explanations for these differences may be attributable to the increased number of symptoms experienced specifically by women (e.g., infertility, early menopause, menstrual irregularities, osteoporosis; Shah \& Leffler, 2010), as well as food-related gender norms that may add increased stress and hassle to women's daily family experiences (e.g., Hallert et al., 2002). Taking this into account, gender differences were explored within the variables of interest for this study using a series of One-way ANOVAs, to determine whether it was appropriate to include both male and female Celiacs when testing the proposed hypotheses. Analyses revealed that male Celiacs were significantly less adherent to the GFD in general $(F(2,209)=3.15, p<.05)$ and reported significantly higher endorsement of Dietary Approach $(F(2,195)=2.72$, $p<.05)$ and Avoidance $(F(2,198)=3.02, p=.05)$ Motives for dietary sacrifice than their female counterparts. This may imply that the Celiac men in this group were more likely to deviate from their prescribed diet than Celiac females. Thus, in order to clarify and 
more easily interpret the results of this study, data from the male Celiacs were excluded from the dataset.

The final sample consisted of 152 cohabitating couples $(69.3 \%$ married; $94.8 \%$ heterosexual; see Tables 1 and 2). The average relationship duration was 11.13 years $(S D=10.78)$ and average number of years cohabitating was $9.56(S D=10.78)$. The majority of Celiacs $\left(M_{\mathrm{Age}}=34.46, S D=11.51 ; 92 \%\right.$ White $)$ had been diagnosed between three and 10 years prior (52.3\%) via intestinal biopsy (85\%). These characteristics fall closely in line with prior epidemiological studies of CD (e.g., Fasano et al., 2003; Leffler et al., 2007) indicating that the recruited sample was representative of the larger Celiac population. Though seven of the remaining couples were homosexual, lesbian relationships, no significant differences were found between these and the heterosexual couples on any variables of interest, and their inclusion did not significantly affect any of the model results; thus, excluding their data from the proposed analyses was deemed unnecessary.

Recruited couples who reported valid zip codes $(k=141)$ hailed from 35 states and represented 136 cities across the United States; there were only five cities in which more than one couple resided (range $k=2$ to 5). No significant differences were revealed between states on the variables of interest to this study. It is important to note that for the couples who reported invalid zip codes (i.e., entered four-digit numbers; $k=11$ ) both partners still reported the same number. Thus, it was assumed that using a number other than their actual zip code was done so to protect their anonymity while providing a matching numerical code, as requested. 
Participants were well-educated, with $29 \%$ of Celiacs reporting to have a Graduate or professional degree (26\% some college and 19\% Bachelor's degree) and $29 \%$ of non-Celiacs $\left(M_{\text {Age }}=38.28, S D=11.65 ; 91 \%\right.$ White $)$ having a Bachelor's degree (27\% some college and $20 \%$ Graduate or professional degree). The majority of couples lived in households with two adults $(88.8 \%)$ and no children (64.7\%). Fifty-two percent of couples reported a household income exceeding $\$ 71,000$. Couples typically ate at least one meal together each day (90.8\%), and women reported being responsible for at least half of the weekly family food purchases and preparations (97\%). See Tables 1 and 2 for a comprehensive overview of sample characteristics.

\section{Procedures}

Eligible Celiacs and their partners were invited to take part in a one-time online survey, hosted through Qualtrics ${ }^{\odot} 2013$. Individuals first indicated their agreement to participate by checking a box at the base of the informed consent page prior to advancing to the questionnaire (see Appendix B). Participants who met the screening criteria were then asked to submit their own and their partners' email addresses, birthdates, and zip codes to be used for matching purposes. This information was purged from the final dataset, except in the case that the partner indicated willingness to participate in future research at the end of the survey. These "willing" participants were asked to reenter their email addresses for verification of their wanting the contact information retained; these data were then stored in a separate, password-protected file immediately following dyadmatching procedures. In total, the survey took no longer than 40 consecutive minutes to complete. 
Once the first participating member of the couple submitted their survey, the second member was emailed an invitation to participate (see Appendix C) within 12 hours, which included a web link. An additional message was sent to the original participant thanking them for their support of the study (see Appendix D), and also informing them that their partner had just received an emailed invitation and that they were encouraged to remind them to participate in the study if they felt comfortable doing so.

\section{Measures}

Responses to the following measures were analyzed for the purpose of testing the proposed hypotheses (see Appendix E for a full list of survey measures):

Demographics. Data were collected regarding participants' age, gender, sexual orientation, ethnicity, household income, marital status, number of children in the household, education level, as well as the duration of the relationship and length of cohabitation. Celiac-specific questions focused on the nature of the diagnosis and number of years since being diagnosed. Additional descriptive questions probed into couples' shared diet behaviors (i.e., primary food preparer and purchaser, number of shared meals per day).

Perceived Dietary Adherence. Participants' level of Adherence to the GFD was measured using two items to determine how adherent they were in general ("Please choose the answer that best describes your gluten free diet Adherence") and specifically when dining with their partner ("Please choose the answer that best describes your gluten free diet Adherence when you are eating a meal with your significant other"). The 
original, individual-based item was created and validated by Leffler and colleagues (2008), and was designed to measure Adherence based on a 6-point Likert-type scale. The relationship-focused iteration was created for use in this study, as it more closely aligns with the phenomenon of interest.

Objective Dietary Adherence. Objective Adherence to the GFD was assessed for the Celiacs using the Celiac Dietary Adherence Test (CDAT; $\alpha=.89$ ). This 7-item measure was created by Leffler and colleagues (2009) as an accurate estimator of actual, rather than perceived, GFD Adherence for patients. The questions are based in symptomology (e.g., "Have you been bothered by low energy level during the past 4 weeks?"), attitudes toward the diet (e.g., "How important to your health are gluten exposures?"), and intention to cheat (i.e., "Over the past 4 weeks, how many times have you eaten foods containing gluten on purpose?"). Responses were reported on a 5-point Likert scale, recoded so that lower scores would reflect poorer Adherence, and summed to create a composite variable. Scores of objective Adherence were positively and significantly correlated with Celiac participants' subjective ratings in this sample $(r(151)=.28, p<.001)$. Eighty percent of participants reported CDAT scores of less than 13, indicating 'Excellent' or 'Very Good' Adherence.

Approach/Avoidance Motives for Dietary Sacrifice. This subscale of the sacrifice motives measure was introduced by Impett, Gable, and Peplau (2005) to assess romantic partners' impetus for ceding their own interests in relationship interactions. The original measure presents participants with the phrase, "On occasions when I sacrifice for my current partner, I generally do so because..." These instructions were adapted for the 
current study to read, "On occasions when I sacrifice for my current partner by eating the same foods as them even when I don't want to, I generally do so because..." This alteration was made with the intention of directing participants to specifically focus on dietary sacrifice rather than more general examples. The Motives for Sacrifice scale is divided into eight items to measure Approach Motives (e.g., "I want to develop a closer relationship with my partner.") and seven items to assess Avoidance Motives (e.g., "I feel guilty if I do not sacrifice.”), with responses indicated on a 5-point Likert scale ranging from 1 (never) to 5 (all the time).

In this study, both the Dietary Approach ( $\alpha=.97$ Celiacs, .89 non-Celiacs) and Dietary Avoidance ( $\alpha=.84$ Celiacs, .78 non-Celiacs) subscales displayed strong internal consistency. The original subscales for general sacrifice motives were also included in the survey and produced acceptable alpha coefficients (Approach $\alpha=.76$ Celiacs, .75 nonCeliacs; Avoidance $\alpha=.78$ Celiacs, .77 non-Celiacs). The Dietary Approach subscale scores were significantly correlated with General Approach scores $\left(r_{\text {Celiacs }}(151)=.21\right.$, $\left.p<.01 ; r_{\text {non-Celiacs }}(151)=.60, p<.001\right) ;$ and, similarly, Dietary Avoidance ratings were significantly correlated with General Avoidance ratings $\left(r_{\text {Celiacs }}(150)=.40, p<.001 ; r_{\text {non- }}\right.$ Celiacs $(151)=.72, p<.001)$. These associations confirm that the new dietary versions of the subscales, while still highly related to the previous iterations, remain distinct. Thus, the diet-focused version of the Motives scale displayed acceptable reliability and concurrent validity for use in this study.

Relationship Satisfaction. Five items from the Investment Model Scale (Rusbult, Martz, \& Agnew, 1998) were used to gauge participants' level of Relationship 
Satisfaction. These items have been implemented in multiple studies of relationship sacrifice (e.g., Impett, Gable, \& Peplau, 2005; Kogan et al, 2010). For this scale, participants were provided with statements such as, "Our relationship makes me very happy", and responses were indicated on an 8 -point scale $(0=$ do not agree at all, $8=$ agree completely). In this sample, reliability proved strong for both Celiacs $(\alpha=.93)$ and nonCeliacs $(\alpha=.91)$.

Depression. Depression has been included as a control variable within the proposed models to address multiple findings indicating that the presence of this psychological state can void the benefits of support received from others (Cutrona, 1996, 1998). Depression has also been recognized as a symptom of poor dietary Adherence for Celiacs, likely as a result of malabsorption and nutritional deficiencies (e.g., Bushara, 2008; Hallert et al., 1998). Thus, it was important to examine the potential confounding nature of this variable. Depression levels were assessed using the Short DepressionHappiness Scale (Joseph, Linley, Harwood, Lewis, \& McCollam, 2004). Participants were asked to rate how often they had experienced each of six characteristics of happiness (e.g., "I felt pleased with the way I am") or Depression (e.g., "I felt cheerless") within the past seven days. Responses were reported on a 4-point Likert scale, ranked from 'Never' to 'Often'. The happiness items were recoded so that the aggregate scale score reflected Depression, with higher scores indicating that the participant experienced more depressed thoughts. In this study, the measure produced an alpha of .84 for Celiac participants and .82 for the non-Celiacs, indicating strong reliability. 


\section{Celiac Testimonies}

An unanticipated and exciting consequence of recruiting online was that the

Facebook posts allowed a forum for Celiac patients to discuss their own personal experiences with GFD adherence within their relationships, and what their partners' willingness (or unwillingness) to support the diet meant to them. Because posts made to Facebook are public unless otherwise indicated, these responses were collected and categorized based on their point of origin $\left(\mathrm{N}_{\mathrm{NFCA}}=15 ; \mathrm{N}_{\mathrm{CDF}}=12\right)$. The qualitative information was not formally coded or analyzed for this study, but is rather being shared to supplement the larger framework as a form of descriptive information. These entries aid in further defining dietary sacrifice and highlighting the significance of the phenomenon within the Celiac population.

Individuals in GFD-supportive relationships wrote of the satisfaction experienced as a result of their partner sharing in their diet. For instance, one wrote that her partner was "the only person I feel that is not trying to contaminate me!" Another wrote, "I have a wonderful man that worries about my health, is considerate to my needs and goes out of his way to make sure that I'm safe from any cross contamination.” Participants with sacrificing partners described their mates as their "best support system," "always looking out for them," and the "absolute best." One comment was particularly insightful in describing the importance of sharing in the diet for this particular population:

My husband is awesome, and in fact, my entire family, grown boys, are now only eating GF in the house. That being said, it most definitely affects your relationship. If my husband is eating glutinous food outside of the home, then 
comes home, I can't kiss him. You lose the spontaneity. Unless your partner is $100 \%$ GF, you always have to be careful. It's also difficult on the gluten eating spouse and family members when it comes to eating out, entertaining etc. I can only imagine being single and having to deal with all of this. It's complicated, that's for sure.

One individual spoke of her positive experience with a partner who, while he does not always eat GF with her, goes out of his way to ensure she is supported in her diet. She wrote, "He always is on the lookout for my fav gluten free goodies every time he shops without me asking. When it's my time of the month he brings me my fav gluten free muffins and chocolate. He even eats a lot of my gluten free things I bake and is starting to like it the more he has it." Some participants in the forum also added comments in response to others' posts in the form of advice. The father of a Celiac daughter who will soon be married to a "beautiful future some-in-law" offered that, "[Celiac relationships] start with unconditional love, compassion, and understanding! The game is playable once those things are intact!" A Celiac female then interceded that "If something such as your dietary restrictions is "destroying" your relationship, I am inclined to believe the issues are deeper than the diet," implying that the negative consequences of lacking support may be a symptom of a larger problem rather than the problem. She also shared that her boyfriend is "more than willing to eat and live a GF lifestyle" when they are dining together.

Others wrote of the negative consequences of having a partner who is unsupportive of the diet. Regarding GFD adherence in her relationship, one woman 
wrote, "It's a constant struggle. Temptations... I feel like it's in a sense him poisoning me." Another spoke of the feelings of unfairness she experiences as a result of her partner's eating habits, saying “[He] brings my favorite foods all the time! Eats in front of me, puts the rest in the refrigerator, so I see it every time I open the door. He even expects for me to go thru the drive-thrus to pick it up. UNCOOL!' One person simply wrote, "Can't sleep in the same bed." Additionally, there were some who shared experiences living in a dietarily diverse relationship and the strains experienced by both couple members. A Celiac woman partnered with a vegan man commented, "Fun times NOT!" and one whose husband was recently also diagnosed Celiac wrote that he "blames" her and "thinks he has come out in sympathy Celiac."

The final entry was made by a Celiac woman regarding her dysfunctional past relationship, and the important role dietary struggles played as an indicator of their larger issues. Her passage is interesting, in that her husband would actually eat GF foods but not when they were together, and he would not save any for her to eat. She also mentions that he would buy gluten-containing foods for her to eat, and that he would become jealous when others bought GF foods special for her. Based on prior literature, her relationship may serve as an example of a couple for whom interdependence was quite low; otherwise stated, the partners may have been existing very separately, in more of a zero-sum capacity, rather than actively striving to work as a unit or team (Kelley \& Thibaut, 1978). Therefore, her partners' consumption of GF foods was seemingly not done for or with her, but rather to spite her, disqualifying it from being considered an act of dietary sacrifice. Here is her statement in full: 
My second husband was the worst ever. He didn't care if my food cost more when I had it in the house, he would eat it if he got hungry. When I froze my cookies from my monthly celiac meetings he would eat them too instead of saving them for me. He would eat my gluten free cereals when he had his own to eat. He got jealous if others purchased special gluten free foods for me such as my own daughter or mother. There were many times I had to go without or get sick in secret eating the gluten he got me. I dreaded crossing him or saying anything. He did other things as well that made me wonder. Suffice it to say our marriage only lasted four years. Actions really do speak louder than words. If I do remarry someday I will definitely watch and pay attention to how he treats me in the food department. It says a lot more about their character than you may think.

These volunteered participant stories aid in elucidating the importance of dietary support within Celiac relationships. Aside from the final entry, which aids in beautifully illustrating the complexities surrounding dietary sacrifice and interdependence in relationships, the information offered paints a fairly black and white picture: dietary support results in positive perceptions and lack of support results in negative perceptions of relationship functioning. However, these issues are deeper than simply "negative;" the use of expressions such as poisoning, blame, lost spontaneity, and inability to sleep together or kiss one another points to much larger consequences for the couples. Reversed, one can assume that these Celiacs feel that if their partner were sharing in the diet in some capacity, they could feel safer and less trivialized, be more spontaneous, and experience far greater physical intimacy. Thus, these individuals have described GFD 
support and dietary sacrifice as a crucial component for their relationship to function in a positive capacity. 


\section{Data Analysis}

\section{Tests for Non-Independence}

The degree of non-independence in outcome variables was assessed in order to determine whether dyadic, versus individual-level, analyses would be appropriate. In accordance with recommendations offered by Kashy and Kenny (2000), a Pearson product-moment correlation was produced between the exogenous variables: Celiac and non-Celiac Relationship Satisfaction $(r(151)=.47 ; p<.001)$. Then, a partial correlation was computed examining this association while controlling for the endogenous variables: Celiac and non-Celiac GFD Adherence when dining with their significant other $(r(151)=.51 ; p<.001)$. Results indicated that substantial interdependence exists between the outcomes based on the significant correlation between participant scores even when controlling for the predictors (Kashy \& Kenny, 2000); thus, the APIMeM was confirmed as the most appropriate technique for testing the proposed hypotheses.

\section{Dyad Matching and Data Configuration}

Partners' responses were collected using two versions of the same online survey, allowing, for example, Sally who accessed the link via Facebook and her partner, Frank, who received the link via emailed invitation to submit their responses potentially using the same computer (i.e., shared IP address). It also created an opportunity to match the partners across datasets and more easily merge the information by adding the nonCeliacs' data as "New Variables." During the survey, each participant was asked to submit both their and their partner's primary email address, birthdate, and zip code for matching procedures. Incidentally, this nationwide sample was quite geographically 
diverse, with no two zip codes alike between couples; so, matching was conducted by first partnering zip codes, and then verifying the matches using email addresses and birthdates. Data were structured dyadically, with each row representing one couple and containing information for both partners as recorded within their corresponding columns (e.g., $\mathrm{X}_{1}, \mathrm{X}_{2}, \mathrm{Y}_{1}, \mathrm{Y}_{2}$ ). Dietary motive and Relationship Satisfaction scores were created by summing the corresponding items for those scales, and Dietary Approach and Dietary Avoidance were grand mean centered to aid in interpretation of the reported findings.

\section{Screening for Outliers}

As noted by Osborne and Overbay (2004), outliers can not only increase error variance and reduce statistical power but can also greatly bias estimates that may be of substantive interest to a study. Due to the complexity of the APIMeM and the relatively limited number of couples in the sample, it was important to conduct a thorough screening of the data. An initial inspection of boxplots for the key study variables revealed one extreme value on the single-item measure of GFD Adherence during shared mealtimes. While all other Celiac participants reported the highest two Adherence options on the scale, only one reported the lowest, indicating zero Adherence. Further inspection of this dyad revealed suspicious responses on a variety of key variables. It was determined that their data were likely falsified, and at best untrustworthy, based on their use of the same email address and inconsistent and extreme values (e.g., all " $5 \mathrm{~s}$ " for both the Approach and Avoidance subscale items, all "1s" for Relationship Satisfaction). The removal of this dyad improved the fit and enhanced the significance of some pathways of interest in both models. It is likely that the substantial influence of this 
couples' data was attributable to the small sample size in the study, allowing the reported extreme values to greatly bias model estimates. A follow-up series of Mahalanobis distances for combinations of predictor and outcome variables within- and betweenpersons were computed (Tabachnick \& Fidell, 2007). These tests are specifically designed to account for correlation and covariance among variables, and results revealed no further significant cases of concern.

\section{Structural Equation Modeling}

Four separate APIMeM models were tested. In all models, GFD Adherence (during shared mealtimes) acted as the predictor variable $(X)$ and Relationship Satisfaction as the outcome variable $(Y)$. Structural equation modeling analyses were performed in four steps using AMOS 19, in accordance with recommendations outlined by Ledermann and colleagues (2011). The two fully-saturated versions of the models (see Figures 2 and 3), sans control variables, were tested first and differed only by the mediator (Dietary Avoidance Motives or Dietary Approach Motives); all parameters for these models were then set to equivalent weights and retested to determine whether the direct effects were indeed distinguishable. The models were restructured to include each partner's Depression score as a control variable on his or her own Dietary Motives and Relationship Satisfaction. A correlation was also drawn between partners' Depression variables, and from non-Celiacs GFD Adherence to his or her own Depression. The new versions of the models were also run in AMOS 19, and their respective outputs were examined for model fit. Mediations were assessed using these final versions of the models, based on comparisons between direct and indirect effects (IEs), determined by 
calculating a series of Sobel tests on hypothesized pathways where X and M were significantly associated (see Table 8). Partial mediations were to be identified when the IE and corresponding direct effect were of the same sign; complete mediations were determined when the direct effect, but not the IE, was zero; and inconsistent mediation (or suppression) were to be characterized when the IE and direct effect were of opposite signs and nonzero (Kenny \& Ledermann, 2010). 


\section{Results}

\section{Descriptive Statistics}

The majority of Celiacs indicated that they were "highly compliant" with their required diet over the past 30 days both when dining in general $(96.1 \%)$ and with their partner (94.1\%; see Table 3 for a detailed breakdown of Adherence). As previously noted, the self-report scores were highly and significantly correlated with their objective Adherence scores $(r(151)=.28, p<.001)$, as assessed via the CDAT (Leffler et al., 2009). Non-Celiacs were significantly less adherent to the GFD when dining in general $(61.5 \%$ noncompliant, $24.8 \%$ moderately compliant, and $13.1 \%$ highly compliant with the GFD) versus when dining with their Celiac partner (33.3\% moderately compliant, $54.9 \%$ highly compliant, $11.8 \%$ noncompliant with the GFD; $t(151)=-14.77, p<.001)$. On average, non-Celiacs agreed that they "put a lot of time and effort into making this dietary sacrifice" for their partner $(M=2.57, S D=1.25)$ and that they "frequently make sacrifices like this" for their partner $(M=2.07, S D=1.12)$.

Tables 4 through 6 provide detailed information regarding within- and betweenpartner correlations on the model variables. Non-Celiacs reported significantly higher levels for endorsement of both Approach $(M=20.98, S D=4.27 ; t(151)=-8.53, p<.001)$ and Avoidance $(M=15.84, S D=5.63 ; t(151)=-10.04, p<.001)$ Motives for dietary sacrifice, compared to Celiacs $\left(M_{\text {Approach }}=20.98, S D=12.40 ; M_{\text {Avoidance }}=10.24, S D=4.87\right)$.

Relationship members' Motive scores significantly correlated with one another only for Dietary Approach Motives, but not Avoidance $\left(r_{\text {Approach }}(151)=.18, p<.05\right.$;

$\left.r_{\text {Avoidance }}(151)=.14, p>.10\right)$. Average Relationship Satisfaction scores were nearly identical 
across dyad members $\left(M_{\text {Celiac }}=34.23, S D=6.40 ; M_{\text {non-Celiac }}=34.78, S D=5.44\right)$ and highly correlated $(r(151)=.47, p<.001)$, as is consistent in prior sacrifice literature (e.g., Rusbult \& Buunk, 1993; Impett et al., 2005). These descriptive statistics of the model variables (GFD Adherence, Dietary Approach and Avoidance Motives, and Relationship Satisfaction) and repeated-measures $t$-test results comparing Celiacs' and non-Celiacs' scores can be found in Table 7.

The control variable, Depression, was not significantly correlated with either partners' model variables. However, it was retained in the model as a control variable on Dietary Motives and Relationship Satisfaction as there remained theoretical justification for its inclusion. Thus, when entered into the final model, a direct path was drawn from Depression to Motives and Relationship Satisfaction for each dyad member, respectively. A correlational (curved) pathway was drawn between partners' Depression variables, as well as between non-Celiacs' Adherence and his or her own Dietary Motives.

\section{Model Fit Indices for APIMeM Models}

Figures 4 and 5 depict the two final tested APIMeM models including the Depression control variables and displaying the unstandardized path estimates, to ease interpretability (see Table 8 for detailed description of standardized and unstandardized parameter estimates). Each model observed GFD Adherence for both partners as the initial variables and corresponding Relationship Satisfaction as the outcome variables. The variables in the models differed only by the mediators: Approach or Avoidance Motives for dietary sacrifice. Model fit indices were inspected to determine how well the models fit the data. The recommended cut-off specifications that were used to determine 
whether the proposed APIMeMs were acceptable included a nonsignificant $\chi^{2}$ statistic, a root mean square of approximation (RMSEA) value of .06 or less (at $p<.05$ ), a normative fit index (NFI) value greater than .85, and a comparative fit index (CFI) value greater than .95 (Tabachnick \& Fidell, 2007). In accordance with the recommendation of Ledermann and Macho (2009) all potential direct effects and indirect effects were tested simultaneously. Results indicated that both the Dietary Approach $\left(\chi^{2}(8, N=152)=3.42\right.$, $p=.774 ; \mathrm{NFI}=.99 ; \mathrm{CFI}=1.00 ; \mathrm{RMSEA}=.00)$ and Dietary Avoidance $\left(\chi^{2}(8, N=152)=4.47\right.$, $p=.812 ; \mathrm{NFI}=.98 ; \mathrm{CFI}=1.00 ; \mathrm{RMSEA}=.00)$ models fit the data well.

\section{Actor and Partner Effects}

Dietary Approach Model. Examination of the parameters revealed significant associations regarding dietary sacrifice. Namely, non-Celiacs' GFD Adherence was significantly related to his or her own endorsement of Dietary Approach Motives $\left(\beta=.408, \mathrm{p}<.001\right.$; path $\left.a_{A 2}\right)$, which was significantly related to his or her own Relationship Satisfaction $\left(\beta=.370, \mathrm{p}<.001\right.$; path $\left.b_{A 2}\right)$ as well as Celiacs' Relationship Satisfaction $\left(\beta=.486, \mathrm{p}<.001 ;\right.$ path $\left.b_{P 1}\right)$. Thus, these pathways met the assumptions for testing indirect effects to assess potential mediation (Baron \& Kenny, 1986; Sobel, 1982). A significant direct actor effect also existed between Celiacs' own GFD Adherence and their Relationship Satisfaction $\left(\beta=.141, \mathrm{p}<.05\right.$; path $\left.c^{\prime}{ }_{A 1}\right)$, and a similar direct actor effect approached significance for the non-Celiacs $\left(\beta=.146, \mathrm{p}=.07\right.$; path $\left.c_{A 2}^{\prime}\right)$. As such, $14 \%$ of the variance in Celiacs' and potentially 14\% in non-Celiacs' own Relationship Satisfaction can be explained by their respective Adherence to the GFD.

Dietary Avoidance Model. Results from this model also supported the notion of 
dietary sacrifice as outlined in prior literature. Non-Celiacs' GFD Adherence was significantly related to his or her own endorsement of Dietary Avoidance Motives $(\beta=-$ $.178, \mathrm{p}<.05$; path $a_{A 2}$ ), which was significantly related to his or her own Relationship Satisfaction $\left(\beta=-.364, \mathrm{p}<.001\right.$; path $\left.b_{A 2}\right)$ as well as Celiacs' Relationship Satisfaction $(\beta=-$ $.232, \mathrm{p}<.001$; path $\left.b_{P 1}\right)$. All of these pathways were negative, indicating that greater endorsement of Dietary Avoidance Motives was associated with lesser Adherence and reduced Relationship Satisfaction. These pathways also met the assumptions for testing indirect effects for mediation. A significant direct partner effect was revealed between non-Celiacs' own GFD Adherence and Celiacs' Relationship Satisfaction $(\beta=.141$, $\mathrm{p}<.05$; path $c^{\prime}{ }_{A 1}$ ), and a significant direct actor effect between non-Celiacs' Adherence and their own Relationship Satisfaction $\left(\beta=.197, \mathrm{p}=.01\right.$; path $\left.c^{\prime}{ }_{A 2}\right)$. The positive direction of these paths is likely due to the nature of the APIMeM model whereby in simultaneously controlling for both partners Avoidance Motives, or negative affectivity regarding behavioral engagement, a positive association was revealed between the behavior itself and couple adjustment. Thus, it can be said that $20 \%$ of the variance in non-Celiacs' and 14\% in Celiacs' Relationship Satisfaction can be explained by nonCeliacs' engagement in the GFD.

\section{Hypothesis Testing}

Results were reported based on examination of the direct and indirect effects produced through testing the final APIMeM models, based on recommendations outlined by Ledermann, Macho, and Kenny (2011). Mediations were assessed by way of a series of Sobel tests (Sobel, 1982) calculated for potential mediating pathways where the IV and 
mediator were significantly associated. The resulting indirect effects (IE) and their corresponding pathways are available in Table 8.

Hypothesis 1 (Actor Effect). For the first hypothesis, it was predicted that there would exist a positive and significant actor effect for participants' dietary Adherence on their own Relationship Satisfaction (paths $c^{\prime}{ }_{A 1}$ and $c_{A 2}^{\prime}$ ) for both models, to support the notion that communal Adherence to a shared diet enhances perceptions of couple happiness. Investigation of the results did reveal significant positive actor (direct) effects in the Dietary Avoidance model for the non-Celiac $\left(\beta_{\text {Celiac }}=.081, \mathrm{p}>.10 ; \beta_{\text {non-Celiac }}=.197\right.$, $\mathrm{p}<.01)$, and in the Dietary Approach model for the Celiac $\left(\beta_{\text {Celiac }}=.141, \mathrm{p}<.05 ; \beta_{\text {non- }}\right.$ Celiac $=.146, \mathrm{p}=.067)$.

Hypothesis 2 and Research Question 1 (Partner Effect). The second hypothesis outlined a proposed positive relationship between non-Celiacs' voluntary GFD Adherence (dietary sacrifice) and Celiacs' Relationship Satisfaction (path $c^{\prime} P 2$ ). This association did prove significant in the Dietary Avoidance model $(\beta=.141, \mathrm{p}<.05)$, but not in the Approach model $(\beta=.068, \mathrm{p}=.367)$. Thus, it can be stated that $14 \%$ of the variance in Celiacs' Relationship Satisfaction can be explained by non-Celiacs' Adherence to the GFD during shared mealtimes. The associated research question posited the existence of a converse relationship between Celiacs' Adherence and non-Celiacs' Satisfaction (path $\left.c_{P 1}^{\prime}\right)$. This pathway was nonsignificant in the Dietary Approach model $(\beta=-.099, \mathrm{p}=.176)$, but approached significance in the Dietary Avoidance model $(\beta=-.132, \mathrm{p}=.055)$.

Hypothesis 3 (Actor-Actor Mediation). This hypothesis was the first of the mediating predictions, which sought to explore the influence of partners' motivations for 
dietary sacrifice on the paths between communal Adherence and Relationship Satisfaction. Specifically, Hypothesis 3 stated that dietary sacrifice would be associated with reduced Relationship Satisfaction for the non-Celiac through his or her own endorsement of Dietary Avoidance Motives and heightened through Approach Motives $\left(a_{A 2} \rightarrow b_{A 2}\right)$. Results indicated that this was indeed the case. Non-Celiacs who committed dietary sacrifice to approach positive gains experienced greater Relationship Satisfaction ( $\beta=.147, \mathrm{p}<.001)$, and those who committed sacrifice to avoid negative outcomes reported lower Relationship Satisfaction $(\beta=.098, \mathrm{p}<.05)$. Because the direct effects for each of these respective mediations was the same valence as the IE but remained larger than zero with inclusion of the mediator, it was determined that Approach and Avoidance motives partially mediated the relationship between non-Celiac's Adherence and both couple members' Relationship Satisfaction, meaning they accounted for some, but not all, of the variance explained.

Hypothesis 4 (Partner-Actor Mediation). It was predicted in this hypothesis that dietary sacrifice would be related to Celiacs' Relationship Satisfaction positively through Celiacs' own endorsement of Approach Motives and Avoidance Motives ( $a_{\mathrm{P} 2} \rightarrow$ $\left.b_{\mathrm{A} 1}\right)$. The purpose of this hypothesis test was to determine whether Celiacs' engagement in dietary sacrifice reciprocity might affect the relationship. Unfortunately, in both models the association between non-Celiacs' Adherence and Celiacs' Motives $\left(a_{P 1}\right)$ was nonsignificant $\left(\beta_{\text {Avoidance }}=-.147, \mathrm{p}=.067 ; \beta_{\text {Approach }}=.042, \mathrm{p}=.606\right)$. Thus, it was inappropriate to explore the presence of mediation.

Hypothesis 5 (Actor-Partner Mediation). The final hypothesis predicted that 
Celiacs' Relationship Satisfaction would be related to dietary sacrifice positively through non-Celiacs' endorsement of Approach Motives and negatively through non-Celiacs' endorsement of Avoidance Motives (path $a_{A 2} \rightarrow b_{P 1}$ ). This hypothesis reflects previous findings of increased Satisfaction for the receiving partner as a byproduct of perceiving the sacrifice being made and the motives accompanying it, whether actively or passively. Results revealed that non-Celiacs' endorsement of Dietary Motives mediated the relationship between their dietary sacrifice and Celiac partners' Relationship Satisfaction in both models. In other words, Non-Celiacs who endorsed Dietary Approach Motives for sacrifice had Celiac partners who experienced significantly higher Relationship Satisfaction $(B=.196, p<.001)$; conversely, those who endorsed Avoidance Motives had Celiac partners who were significantly less satisfied with the relationship $(B=.338$, $p<.05)$ 


\section{Discussion}

Prior research on couples' eating behaviors strongly reinforces the notion that partners pursue shared dietary preferences and find value in cooking and eating together. Dietary support literature has historically focused on either chronological trends within relationships (e.g., similarity in food preferences over time) or partners' ability to enable positive and negative eating behaviors among each other during a measurable period of time. Studies of diabetes and cardiovascular disease have commonly investigated which forms of partner support are most beneficial to patients, often finding that dietary support is overwhelmingly noted as the most desirable and helpful. Yet all of these avenues of investigation have thus far failed to delve more deeply into the specific types of dietary support offered and their individual implications on couple functioning. This study has supplied a definable term for a common and specific form of diet support - dietary sacrifice - where one was previously lacking, and has provided substantial evidence for the further empirical exploration of this distinct phenomenon under the umbrella of both relationship sacrifice and communal eating behaviors among couples.

The diagnosis of a food-related disorder like Celiac Disease (CD) poses an interesting point of relationship conflict that has been oft ignored in previous research, wherein couples who are in the process of developing or have already established communal eating patterns are suddenly pressured to decide whether they want to continue maintaining a shared diet - meaning at least one member must compromise their health or preferences, respectively - or adopt independent diets, which may be accompanied by increased family food costs, risk of cross-contamination for the Celiac, and/or negative 
affect. Yet, while the pursuit of shared GFD adherence may seem like an easier option or lesser sacrifice based on these potential alternatives, individuals generally purport holding strong emotional ties to their favorite gluten-rich comfort foods (e.g., macaroni and cheese, pastries, pasta; Wansink, Cheney, \& Chan, 2003; Wallis \& Hetherington, 2009) adding extra psychological cost to the decision to join in a GF regimen.

In the current study, the APIMeM (Lederman et al., 2011) was implemented to explore the implications of dietary sacrifice as a form of relationship support in couples affected by CD. Associations between non-Celiacs' dietary sacrifice and both partners' relationship satisfaction through non-Celiacs' endorsement of Dietary Approach or Avoidance Motives were tested while simultaneously controlling for interdependence between partners' reciprocal variables and actor-partner effects. Results supported findings from prior literature on general relationship sacrifice (e.g., Impett et al., 2005; Impett et al., 2008). Non-Celiacs who adhered to the diet during shared mealtimes to avoid negative experiences produced significantly lower satisfaction scores for both themselves and their partners. Conversely, non-Celiacs who committed dietary sacrifice to promote the health and well-being of their partner produced enhanced relationship satisfaction for both couple members. Thus, the findings provided evidence that treatment support in the form of shared dietary adherence can provide great benefit to Celiac relationships in the case that it is enacted for positive gains. However, communal adherence to the GFD enacted to avoid arguments, curry favor, or increase one's own likeability is not only an ineffective form of support, but may actually hurt both partners' perceptions of their relationship. 
As this study has illuminated, there are indeed situations in which communally investing in the GFD, and thus engagement of the non-Celiac in dietary sacrifice, may negatively impact both partners' experiences of relationship satisfaction. The findings reported here from the Avoidance Motives model can be linked back to prior research of support in romantic relationships, which indicates that the negative impacts of unsupportive interactions weigh heavier on couple functioning than the benefits gained in positive support experiences (e.g., Cutrona et al., 1997). What is particularly interesting here, though, is that while the behavior itself (i.e., communal GFD adherence during shared mealtimes) can be interpreted as objectively supportive, the psychological motives whether obvious or unstated are what may be perceived as non-supportive. The interpretation of this as it relates to relationship satisfaction in some part, then, lies on the Celiac member to determine whether they are in greater need of instrumental or emotional support, and if those needs are being adequately met.

Engagement in dietary sacrifice by way of Avoidance Motives may also test the boundaries of equity and emotional disclosure expectations in relationships. As opposed to honestly discussing issues and concerns surrounding the difficult dietary changes and coming to an amiable compromise, the non-Celiac may instead give into the diet against their will through either imagined or real pressure from the Celiac partner. Thus, the nonCeliac would feel cheated by having to make an unwanted sacrifice and the Celiac would feel worse for having a partner who is emotionally unsupportive in the way that they desire, regardless of the fact that the partner may be behaving in exactly the preferred fashion. Indeed, Impett and Gordon (2008) note that dangers may result from committing 
sacrifices if the sacrificing partner fails to openly communicate their feelings, positive or negative, regarding the action. In attempting to maintain a connection at any cost, some partners may silently accept the performance of behaviors that they do not condone or that run contrary to their preferences, resulting in their experiencing heightened depression and lowered self-esteem (Jack \& Dill, 1992).

Further, recent research on Equity Theory (Adams, 1965) has shown that while perceptions of inequity, whether as a result of imbalance of support or one partner overly sacrificing, is not necessarily indicative of relationship dissolution, it can significantly and substantially diminish partners' marital happiness, especially in women. These negative effects may be further exacerbated by husbands' predilection toward holding individual- rather than communal-orientations regarding household obligations (DeMaris, A., 2007). Since the major assumptions of Interdependence Theory, upon which prior relationship sacrifice literature has been built, rely heavily on the concept of Transformation of Motivation (Kelly \& Thibaut, 1978) which describes individuals' transition to a communal-orientation during times of partner noncorrespondence in a given situation; it is possible that the negative effect of Avoidance Motives on relationship satisfaction is indicative of an inability or unwillingness of the sacrificing partner to psychologically embrace a communal-orientation.

It is important to note that results of the Dietary Avoidance Motives model revealed that when controlling for Avoidance Motives, which can be loosely translated here as negative emotionality regarding the dietary sacrifice, there was a significant direct effect from non-Celiacs' GFD adherence to both their own and their Celiac partners' 
relationship satisfaction. Meaning, the behavior itself does have a positive impact on couple adjustment regardless of why it is being committed in some cases. These findings certainly add to the conversation regarding the types of support most important to these patients and whether a lack of positive emotional support negatively impacts the effects of a sacrificing behavior on relationship satisfaction. Further research is needed to unpack the complexities involved in this behavior versus affect scenario; yet, the results here would suggest that there is some benefit to engaging in dietary sacrifice even when positive, communal motives are lacking.

Results of this study also revealed that, as expected, non-Celiac partners who voluntarily engaged in the dietary changes for want of benefiting their Celiacs' health, happiness, and/or well-being reported experiencing greater positive affect toward their relationships, and their heightened satisfaction was also mirrored by the Celiacs. Plainly speaking, this study has shown that dietary sacrifice performed in the pursuit of positive gains can significantly benefit both partners' evaluations of relationship satisfaction. These results align with prior sacrifice findings revealing positive outcomes for couples who perform sacrificing behaviors through General Approach Motives, but unlike previous work in this area, with the exception of Impett and colleagues' explorations of sexual sacrifice (e.g., Impett \& Peplau, 2003), this study has been the first to explore the implications of one specific type of accommodative health behavior. The findings produced here provide credence to the notion that joint diet adherence as a form of support constitutes a legitimate and distinct behavior which can be compared to other more commonly studied forms of relationship support in future research. 
One additional point of novelty in this study was the use of an exclusively female Celiac sample, as it was ultimately decided that the general experience of dietary sacrifice within this population would not be consistent between genders due to variation in experiences regarding the illness, as well as a low proportion of recruited male patients. Previous research on CD and well-being has consistently indicated that women experience lower quality of life levels, a higher burden of disease, and elevated scores of depression and anxiety (e.g., Hallert et al., 2002). In general, women are also significantly more often the primary food preparers in the household, and tend to perform the bulk of food-related chores (Blair \& Johnson, 1992; Perry-Jenkins, Newkirk, \& Ghunney, 2013; Tang \& Curran, 2013). Yet, despite all of this, no studies had been performed to date to explore the experiences and implications of Celiac management for female patients specifically.

Because this study employed a sample of exclusively female Celiacs, and women tend to prefer comfort and ego support from their romantic partners rather than persuasive or instrumental support (Burleson, 2003; Wood, 1993), it is difficult to know whether there may have been significant differences within- and between-partners based on gender without recruiting a larger sample of male patients. Although, it should be noted that there is no current evidence to suggest the presence of gender differences in expressions of general sacrifice between partners or effects of sacrificing behavior on the relationship. Prior studies of sacrifice have either omitted gender findings altogether (Gable \& Impett, 2012; Impett et al., 2012; Kogan et al., 2010), or tested for gender 
effects and found no significant or theoretically meaningful differences (Impett, Gable, \& Peplau, 2005; Impett et al., 2010; Van Lange et al., 1997a, 1997b).

Whiton, Stanley, and Markham (2007) further reported that men and women do not differ significantly in perceptions of their frequency of sacrifice; although they did find that females rate sacrifices related to household chores as more harmful than did men, and males rate sacrifices related to listening sympathetically to complaints and venting as more harmful than females. This suggests the possibility that individuals performing sacrifices that run counter to their gender norm expectations may experience more distress; however, these findings do not necessarily relate to the type of sacrifice explored in this study, as the focus here was on eating behaviors specifically which are equally enacted by both men and women. Had this study also included cooking and shopping for GF foods - activities which run counter to male gender normative behavior - as forms of sacrifice there may have been higher incidence of Avoidance Motives among non-Celiac males versus females and potentially lowered relationship satisfaction for both partners. Therefore, while it is recommended that future studies recruit a larger proportion of male patients to explore gender effects, it is not expected that there will be substantial or significant differences for this particular phenomenon based on prior literature. Perhaps the only difference to be expected, referencing the increased burden of disease experienced by female Celiacs compared to males, is that women may have a higher need or desire for dietary sacrifice from their partners that could lead to differential relationship satisfaction results between patients.

Interestingly, the men in this study reported, albeit subjectively, a higher-than- 
expected incidence of GFD adherence when dining with their Celiac partners. This overwhelming presence of dietary sacrificing behavior arguably runs contrary to findings and beliefs stated in prior studies of health-supportive behaviors wherein men are generally found to be significantly less likely to perform sacrifices (e.g., picking up prescriptions; Umberson et al., 1996). In fact, Impett and Gordon (2008) recommended that future researchers explore health-related avenues by which men are likely to engage in sacrificing behavior. The findings produced here certainly at least partially address that request; although, without the ability to compare to females' likelihood to engage in dietary sacrifice to males' it is difficult to make any substantive statements to that end. While future research would certainly benefit from thoroughly probing Celiac-supportive gender differences, and specifically investigating the influence of gender on attitudes toward the GFD, dietary knowledge, desire for partners' dietary sacrifice, and household chore delegation as they potentially affect relationship and dietary support processes; it is believed that the use of an exclusively female patient sample was a benefit to the current exploratory investigation. The information gathered here may aid in advancing knowledge regarding the promotion of support processes that are particularly helpful for this subset, which represents fully two-thirds of the overall Celiac population.

Generally speaking, the act of engaging in restrictive dieting behaviors is so overwhelmingly common and varied between Americans (Anderson \& Gustafson, 1989; Markey, Markey, \& Birch, 2001) that conducting this first study of dietary sacrifice within the general population could have introduced a multitude of confounding variables. Specifically, it would have been extremely difficult to pinpoint, describe, or 
control for differences between participants' dietary goals. Celiacs have one specific eating requirement: exclude all gluten-derivative ingredients from their diet (Leffler et al., 2007). Thus, recruiting within this patient community provided measurable consistency between the dieters, which aided greatly in the ability to gather adherence information and interpret the findings.

However, it should be noted that the effects of dietary sacrifice within the Celiac population may present far differently than in other diet-related groups. One of the interesting facets of CD is the immediacy of symptom presentation following gluten ingestion for those who are adamantly adherent to the GFD. For these individuals, a mere crumb of wheat can trigger an onslaught of debilitating neurological (e.g., migraine headaches) and/or gastrointestinal (e.g., severe gas, diarrhea, bloating) outcomes that may last anywhere from one week to one month before fully subsiding. Thus, crosscontamination concerns within and outside of the household are provided immediate legitimacy to those closest to the patient, potentially contributing to an unspoken argument for shared GFD adherence. Other diet-centric illnesses, such as diabetes and cardiovascular disease, have negative implications for nonadherence that present in a much longer-term fashion. Well-partners of patients in these groups may be less likely to consistently communally adhere to the prescribed diets, because the reasons for doing so are less obvious. For the purpose of this argument, perhaps it makes more sense to relate CD to an intolerance or allergy rather than a chronic illness, which it in fact is. The partner of someone with a bee-sting allergy need only administer an Epinephrin shot once to understand the importance of avoiding gardens in the Spring. Future studies of dietary 
sacrifice must strive to account for the presentation and intensity of outcomes resulting from nonadherence for the specific population of interest in order to paint a clear picture of the phenomenon. The well-partners' willingness to sacrifice, the dieting partners' desire for that sacrifice, and the implications of the interaction could appear far differently depending upon the group or interaction being investigated.

Even outside the realm of diagnosed dieting, the effects of this form of sacrifice could carry varying meaning depending upon the couples' circumstances. Relationships in which partners are noncorrespondent on other diet-related influences, such as religion, may enact and execute dietary sacrifice in their own unique ways. Coupled with this thought, there are also circumstances in which the non-restricted partner may engage more adamantly in the dietary restrictions than the affected partner. For example, John has become engaged to Hilda and is considering converting to Judaism for her, so he wholeheartedly commits to maintaining a completely kosher diet; but Hilda, having been raised in the faith considers herself more of a fair-weather follower, and loves to eat a good cheeseburger at least once a week. Technically, John could be engaging in dietary sacrifice - he is committing to the religious dietary laws of his fiancé - however, she may not consider this act to be beneficial; or worse, she may even consider it a nuisance. Studies of cardiovascular disease recovery (Tapp, 2004) and diabetes maintenance (Trief et al., 2003) have shown that dietary support from intimate partners can run the risk of coming across to the patient as nagging or annoying. Yet, again, these studies have not looked specifically at dietary sacrifice (or communal adherence), but rather on general diet-supportive behaviors (e.g., cooking and shopping for healthy foods). Thus, the 
identification of dietary sacrifice as a distinct supportive phenomenon in this study provides a base from which future studies can expand the exploration of this behavior to other couple circumstances and patient populations.

\section{Implications}

The results of this preliminary study provide a basis for better understanding the implications of dietary sacrifice for female Celiac patients and their non-Celiac partners; but, beyond that, they provide strong support for the need of practitioners to thoughtfully frame diet-related health messages to the Celiac community. Certainly, obtaining beneficial dietary support in the form of shared GFD adherence is not as simple as making a request of the non-Celiac partner. Such a request could result in a sense of obligation to adhere or a desire to avoid food-related arguments (i.e., engagement in Avoidance Motives), thus resulting in adverse relationship outcomes for both members which could lead to increased burden of illness for the patient. Indeed, the suggestion or request needs to be made with both the needs and dispositions of the patient and their partner in mind, so that engagement in dietary sacrifice is Approach- rather than Avoidance-motivated.

Studies of health-message framing through the lens of the Congruency Hypothesis (or Effect) aid in outlining one avenue practitioners may pursue when discussing GFD adherence strategies with Celiac patients (Mann, Sherman, \& Updegraff, 2004; Sherman, Mann, \& Updegraff, 2006). Within this framework, Approach and Avoidance tendencies are studied as traits, or individual orientations, rather than situation-specific motivations. Approach-oriented individuals, high in "hope for affiliation," are described 
as those with a tendency to enter situations in the pursuit of positive outcomes; whereas, Avoidance-oriented individuals, those high in "fear of rejection," engage in social interactions with the want to avoid negative consequences (Impett \& Gordon, 2008; Mehrabian, 1976). Participants are provided health advertisements that correspond to these dispositions, and subsequent engagement in that behavior (e.g., flossing) is measured. Findings from these studies overwhelmingly suggest that the most effective way to elicit a desired health behavior, in this case dietary sacrifice, from an individual is to employ a message or request that corresponds with his or her Approach-Avoidance disposition (Gallagher \& Updegraff, 2011).

Thinking about this within the framework of communal GFD adherence, a newlydiagnosed Celiac in a relationship with an Approach-oriented partner should be more likely to elicit dietary sacrifice by emphasizing the benefits of shared adherence (gainframed message): "When you eat GF foods with me, it helps me adhere to my diet better and I feel a lot healthier! It also means I can kiss you more, because I'm not worried about whether you've eaten gluten. It's a win-win!” An Avoidance-oriented partner should, conversely, be more likely to respond to a message that outlines the potential dangers of not adhering to the GFD (loss-framed message): "When you eat GF foods with me, I'm at less risk for cross-contamination which ensures that I won't suffer from debilitating and embarrassing neurological and gastrointestinal symptoms. We also wouldn't need to avoid eating out as much, because us sharing in the diet makes me feel less stigmatized in public.” These disposition-congruent messages, posed strategically and lovingly (i.e., no nagging, arguing, or belittling), should trigger non-Celiac partners' 
desire to voluntarily adhere for the pursuit of positive gains which would thus benefit the couple.

However, due to difficulties in identifying Approach-Avoidance dispositions without intimate knowledge of an individual or administration of the BIS/BAS Scale (Carver \& White, 1994), practitioners would likely also benefit from actively listening to their patients and aligning their advice for eliciting partner GFD support with items from the Approach-Avoidance motivation subscales included in this study (Impett, Gable, \& Peplau, 2005). For example, if one is attempting to encourage a non-Celiac partner to adhere to the new Celiacs' GFD, they might use statements such as, "if you decide to adhere, do so because... you want your partner to be happy; you truly enjoy sharing the diet with them; you want to develop a closer relationship; and you are concerned about their health and well-being." Statements to avoid include, "you will feel guilty or anxious if you don't adhere; your partner will love you more if you adhere; and your partner will be angry if you don't adhere." If a practitioner feels uncomfortable speaking directly to the non-Celiac partner, or if they are not present at an appointment, these suggestions can be made to the Celiac patient as ways to initiate a conversation with their partner; ultimately keeping in mind that the goal of these messages, regardless of who is initiating them, is to trigger voluntary sacrifice through Dietary Approach Motives.

\section{Limitations}

While the demographic characteristics and objective GFD adherence scores of this sample were consistent with prior epidemiological and demographic investigations of Celiac in the United States (e.g., Leffler et al., 2009; Fasano, et al., 2003), by recruiting 
participants exclusively from Celiac support websites and organizations it is possible this study suffered self-selection bias. Prior studies of Celiac have failed to include data regarding the educational and financial status of their participants, so it is difficult to fully assess whether the highly affluent nature of those in this study reflect the larger population, or if this trend was a result of recruiting from online organizations and thus excluding those who cannot afford computers or reliable Internet service. Future researchers would benefit from seeking patient participants through more direct healthrelated routes, such as hospitals and markets.

The use of a slightly adjusted version of the General Approach and Avoidance Motives scale to gauge dietary sacrifice is one aspect of the methodology in this project that may require some adjustment in future studies of dietary sacrifice within patient populations. The altered instructions for the measure simply asked participants to indicate their motives when "eating the same foods as [their partner] even when [they did not] want to." While this version of the original questionnaire (Impett et al., 2005) may work well in the general population, and indeed did produce the expected distributions within the non-Celiac subsample, it may not have fully addressed the motivations of the Celiacs nor provide adequate instructions for how to appropriately respond. That is, it is possible a Celiac participant may have assumed the goal of the measure was to gauge reasons for cheating on their prescribed diet or committing dietary nonadherence rather than, for instance, eating Mexican food when they really preferred Chinese. Since this exploratory investigation was meant primarily to define the phenomenon of dietary sacrifice and inform future studies of daily dietary support processes, it is recommended that 
accommodations be made if implementing this measure with a patient sample in the future.

Kenny and colleagues (2006) noted that cross-sectional designs have overwhelmingly been the most commonly used methodology in dyadic health research. Despite this, it still remains a potential limitation to the current study, as its use restricts the interpretability results by not allowing for establishment of causality. Although the implementation of the APIMeM and theoretical overview have built a strong argument for the pathways as established in this investigation, these findings may prove to be bidirectional or fully reversible with further exploration. Thus, in order to provide as much credence as possible for the models as specified here, reversed versions (e.g., $X_{\text {Relationship Satisfaction }} \rightarrow M_{\text {Approach Motives }} \rightarrow Y_{\text {GFD Adherence) }}$ were also analyzed using AMOS 19. Results indicated that the significant actor and partner effects relevant to the partial mediations found in the initial models remained significant in the reversed versions, but the regression weights were substantially smaller (e.g., Approach Model path $a_{A 2}: \beta=.056$ versus $.408, p<.01)$. In other words, the effects of dietary sacrifice on Relationship Satisfaction for both partners through non-Celiacs' Approach or Avoidance motives were far greater than the effects of both partners' Relationship Satisfaction on GFD Adherence through motive endorsements. The models and results presented in this investigation therefore represent the strongest interpretation of the phenomena, and future investigations using differing designs will likely provide further evidence to this effect.

The results of these analyses are indeed meant primarily to inform the formation of daily diary and longitudinal studies, which can more thoroughly gauge the dynamic 
processes surrounding engagement in dietary changes and establish specific causal links between diet maintenance and support outcomes. Dietary adherence by anyone, including Celiacs, is contingent on multiple contextual and daily elements (e.g., food availability, geographic location, holidays, cross-contamination, presence of supportive/unsupportive others; Sverker et al., 2009). A person's response to questions of dietary adherence may differ between months, days, or even hours. Future studies would thus further benefit from the inclusion of comprehensive context/environment-based questionnaires to address extraneous limitations affecting dietary adherence at any given moment, above and beyond the roles of support offered by significant others.

Finally, this study intentionally employed a sample of participants in established, cohabitating relationships, in an attempt to focus on couples for whom conversion to the GFD was most likely to have caused an interruption in their established communal eating norms (Rappoport, 2003). For these couples, dietary sacrifice may be enacted in an attempt to reestablish a communal dieting pattern, which has been found to be an important part of couple functioning (e.g., Bove et al., 2003). While this decision aided in diminishing extraneous relationship and dining factors, it did limit the ability to delve into the complexities surrounding GFD adherence processes for couples at different stages of their illness and/or relationship. For example, a new relationship initiating close to the time of the Celiac's diagnosis may fall prey to difficulties involved in finding GFfriendly restaurants and creating boundaries to avoid cross-contamination - the Celiac may not have had time to learn enough about their illness yet to be able to inform the new partner. Or, conversely, the new couple may bond over the diagnosis and enjoy the 
challenge of navigating the new diet together, which may lead to a stronger relationship in the long-term (Meichenbaum, 1985; Neff \& Broady, 2011). As future studies construct more complex methodologies to explore dietary sacrifice, inclusion of couples with varying circumstances surrounding diagnosis and relationship/cohabitation duration would add some much needed complexity to the study of this as a close relationshiprelevant phenomenon.

\section{Conclusion}

In conclusion, despite the limitations to the current research, the results of this study have produced multiple benefits for sacrifice, health, and relationships knowledge. This was the first investigation to attempt defining a health-specific form of sacrifice, the testing of which fell nearly directly in line with previous findings regarding general daily sacrificing behaviors in relationships. Thus, these results provide ample motivation to test this support process within the general population or other diet-related patient samples using longitudinal or daily methodological approaches to further substantiate the phenomenon. This was also the first exploration into relationship-relevant factors pertaining to dietary adherence for the Celiac population. While other studies of this group have mentioned the vague possibility of a family and partner impact (e.g., Sverker et al., 2009), none have specifically measured or tested the effects of others' support on Celiacs' ability to cope with the illness. These findings provide legitimacy to the idea that cohabitating partners and spouses of Celiacs do play a significant role in maintenance of the GFD, and have revealed that many non-Celiacs are voluntarily adhering to the diet during shared mealtimes. It would be interesting to investigate, in future studies, whether 
this decision to commit dietary sacrifice is more a result of wanting to maintain a tradition of communal meals, avoiding the need to cook separate meals for each partner, or for more traditional Approach-Avoidance Motives for sacrifice, as was the focus here. In summary, these findings aid in identifying dietary sacrifice as a unique facet of general relationship sacrifice that potentially impacts all relationship experiences on a daily level. 
Table 1

Demographics of Individual Partners $(k=152)$

\begin{tabular}{|c|c|c|c|c|}
\hline \multirow[b]{2}{*}{ Characteristics } & \multicolumn{2}{|c|}{ Celiac } & \multicolumn{2}{|c|}{ Non-Celiac } \\
\hline & $\mathrm{N}$ & $\%$ & $\mathrm{~N}$ & $\%$ \\
\hline Age $(M \pm S D)$ & \multicolumn{2}{|c|}{$36.46 \pm 11.51$} & \multicolumn{2}{|c|}{$38.28 \pm 11.65$} \\
\hline \multicolumn{5}{|l|}{ Sexual Orientation } \\
\hline Heterosexual & 137 & 89.5 & 146 & 96.0 \\
\hline Homosexual & 5 & 3.3 & 5 & 3.4 \\
\hline Bisexual & 9 & 5.9 & - & - \\
\hline \multicolumn{5}{|l|}{ Ethnicity } \\
\hline White & 141 & 92.2 & 139 & 90.8 \\
\hline Black/African American & 1 & 0.7 & 2 & 1.3 \\
\hline Latino & 8 & 5.2 & 4 & 2.6 \\
\hline American Indian/Alaskan Native & 3 & 2.0 & 2 & 1.3 \\
\hline Asian & - & - & 4 & 2.6 \\
\hline Other & 7 & 4.6 & 3 & 2.0 \\
\hline \multicolumn{5}{|l|}{ Education } \\
\hline High School/GED & 10 & 6.5 & 12 & 7.8 \\
\hline 2-year Degree (A.A., A.S., etc.) & 14 & 9.2 & 19 & 12.4 \\
\hline Some College, No Degree & 40 & 26.1 & 41 & 26.8 \\
\hline Bachelor's Degree & 29 & 19.0 & 44 & 28.8 \\
\hline Some Graduate Study & 14 & 9.2 & 5 & 3.3 \\
\hline Graduate or Professional Degree & 44 & 28.8 & 31 & 20.3 \\
\hline
\end{tabular}


Table 2

Demographics of Dyads $(k=152)$

\begin{tabular}{lcc}
\hline Characteristics & $\mathrm{N}$ & $\%$ \\
\hline Married & 106 & 69.3
\end{tabular}

Household Income

$\begin{array}{lcr}<\$ 16,000 & 9 & 5.9 \\ \$ 16,000-\$ 27,000 & 7 & 4.6 \\ \$ 27,001-\$ 44,000 & 26 & 17.0 \\ \$ 44,001-\$ 71,000 & 29 & 19.0 \\ \$ 71,001-\$ 132,000 & 46 & 30.1 \\ \$ 132,001 \text { or More } & 34 & 22.2\end{array}$

Adults in Household

Two

Three

$11 \quad 7.2$

Four

$3 \quad 2.0$

Five or more

$3 \quad 2.0$

Children in Household

Zero

99

64.7

One

$14 \quad 9.2$

Two

$31 \quad 20.3$

Three

$\begin{array}{ll}6 & 3.9\end{array}$

Four

2

Frequency of Communal Meals (past month)

Ate all meals together each day

Ate some meals together each day

Ate one meal together each day

$49 \quad 32.0$

Did not eat meals together on a regular basis

69

45.1

$14 \quad 9.2$

Proportion of Responsibility for Food Preparation

Most or all

About half

80

52.3

Little or none

69

41.1

$4 \quad 2.6$

Relationship Duration in Years $(M \pm S D)$

$11.14(10.79)$

Cohabitation Duration in Years $(M \pm S D)$

$9.56(10.78)$ 
Table 3

Gluten-free Diet Adherence of Individual Partners $(k=152)$

\begin{tabular}{|c|c|c|c|c|}
\hline \multirow[b]{2}{*}{ Context } & \multicolumn{2}{|c|}{ Celiac } & \multicolumn{2}{|c|}{ Non-Celiac } \\
\hline & $\mathrm{N}$ & $\%$ & $\mathrm{~N}$ & $\%$ \\
\hline \multicolumn{5}{|l|}{ Adherence in General } \\
\hline Highly compliant & 144 & 94.1 & 21 & 13.1 \\
\hline Moderately compliant & 9 & 5.9 & 38 & 24.8 \\
\hline Moderately noncompliant & - & - & 20 & 13.1 \\
\hline Highly noncompliant & - & - & 7 & 4.6 \\
\hline Not complying at this time & - & - & 21 & 13.7 \\
\hline Not compliant & - & - & 46 & 30.1 \\
\hline \multicolumn{5}{|l|}{ Adherence when Dining with Partner } \\
\hline Highly compliant & 144 & 94.1 & 84 & 54.9 \\
\hline Moderately compliant & 9 & 5.9 & 51 & 33.3 \\
\hline Moderately noncompliant & - & - & 13 & 8.5 \\
\hline Highly noncompliant & - & - & 5 & 3.3 \\
\hline
\end{tabular}


Table 4

Within-person Correlations for Celiac Partners

\begin{tabular}{lccccc}
\hline Variables & 1 & 2 & 3 & 4 & 5 \\
\hline 1. Depression & - & & & & \\
2. Adherence with Partner & .028 & - & & \\
3. Relationship Satisfaction & .051 & .148 & - & & \\
4. Dietary Approach Motives & .006 & .226 & .062 & - \\
5. Dietary Avoidance Motives & -.060 & .329 & $\mathbf{. . 6 5 2}^{* * *}$ & $\mathbf{. 2 4 8}^{* *}$ & - \\
\hline
\end{tabular}

*p $p .05,{ }^{* *} p<.01,{ }^{* * * *} p<.001$ 
DIETARY SACRIFICE IN CELIAC RELATIONSHIPS

Table 5

Within-person Correlations for Non-Celiac Partners

\begin{tabular}{llcccc}
\hline Variables & 1 & 2 & 3 & 4 & 5 \\
\hline 1. Depression & - & & & \\
2. Adherence with Partner & .009 & - & & \\
3. Relationship Satisfaction & .020 & $\mathbf{. 2 7 8}^{* *}$ & - & \\
4. Dietary Approach Motives & .046 & $\mathbf{. 4 0 1}^{* * *}$ & $\mathbf{. 4 1 5}^{\text {**** }}$ & - \\
5. Dietary Avoidance Motives & .074 & $\mathbf{. . 1 7 6}^{*}$ & $\mathbf{- . 4 2 5}^{\text {**** }}$ & -.127 & - \\
\hline
\end{tabular}

${ }^{*} p<.05,{ }^{* *} p<.01,{ }^{* * *} p<.001$ 
DIETARY SACRIFICE IN CELIAC RELATIONSHIPS

Table 6

Between-person Correlations Comparing Non-Celiac and Celiac Partners

\begin{tabular}{|c|c|c|c|c|c|}
\hline Celiac & \multicolumn{5}{|c|}{ Non-Celiac } \\
\hline Variables & 1 & 2 & 3 & 4 & 5 \\
\hline 1. Depression & -.066 & -.079 & .098 & .076 & .027 \\
\hline 2. Adherence with Partner & .009 & .128 & -.086 & .007 & -.007 \\
\hline 3. Relationship Satisfaction & -.051 & $.280^{* * * *}$ & $.469^{* * * *}$ & $.506 * * *$ & $-.339^{* * * *}$ \\
\hline 4. Dietary Approach Motives & .123 & .055 & -.015 & $.184^{*}$ & .023 \\
\hline 5. Dietary Avoidance Motives & .020 & -.149 & $-.295^{* * *}$ & $-.367^{* *}$ & .138 \\
\hline
\end{tabular}

${ }^{*} p<.05,{ }^{* *} p<.01,{ }^{* * * *} p<.001$ 
Table 7

Between-partner Descriptive Statistics, Correlations, and Pairwise t-tests

\begin{tabular}{|c|c|c|c|c|c|}
\hline & \multirow[b]{2}{*}{$M$} & \multirow[b]{2}{*}{$S D$} & \multirow[b]{2}{*}{$r$} & \multicolumn{2}{|c|}{ Pairwise $t$-tests } \\
\hline & & & & $t(d f=151)$ & $d$ \\
\hline Celiac Diet Adherence & 5.94 & 0.24 & .128 & $8.53^{* * * *}$ & 0.94 \\
\hline Non-Celiac Diet Adherence & 5.40 & 0.78 & & & \\
\hline Celiac Approach Motives & 20.98 & 12.40 & $.184^{*}$ & $-13.38^{* * *}$ & 1.44 \\
\hline Non-Celiac Approach Motives & 34.34 & 4.27 & & & \\
\hline Celiac Avoidance Motives & 10.24 & 4.87 & .138 & $-10.04^{* * *}$ & 1.06 \\
\hline Non-Celiac Avoidance Motives & 15.84 & 5.63 & & & \\
\hline Celiac Satisfaction & 34.23 & 6.40 & $.469^{* * * *}$ & -1.14 & 0.09 \\
\hline Non-Celiac Satisfaction & 34.78 & 5.44 & & & \\
\hline Celiac Depression & 6.62 & 15.50 & -.066 & .65 & 0.08 \\
\hline Non-Celiac Depression & 5.50 & 13.64 & & & \\
\hline
\end{tabular}

Note. $M=$ Mean, $S D=$ Standard Deviation, $d f=$ Degrees of Freedom, $d=$ Cohen's $d$. ${ }^{*} p<.05,{ }^{* *} p<.01,{ }^{* * * *} p<.001$ 


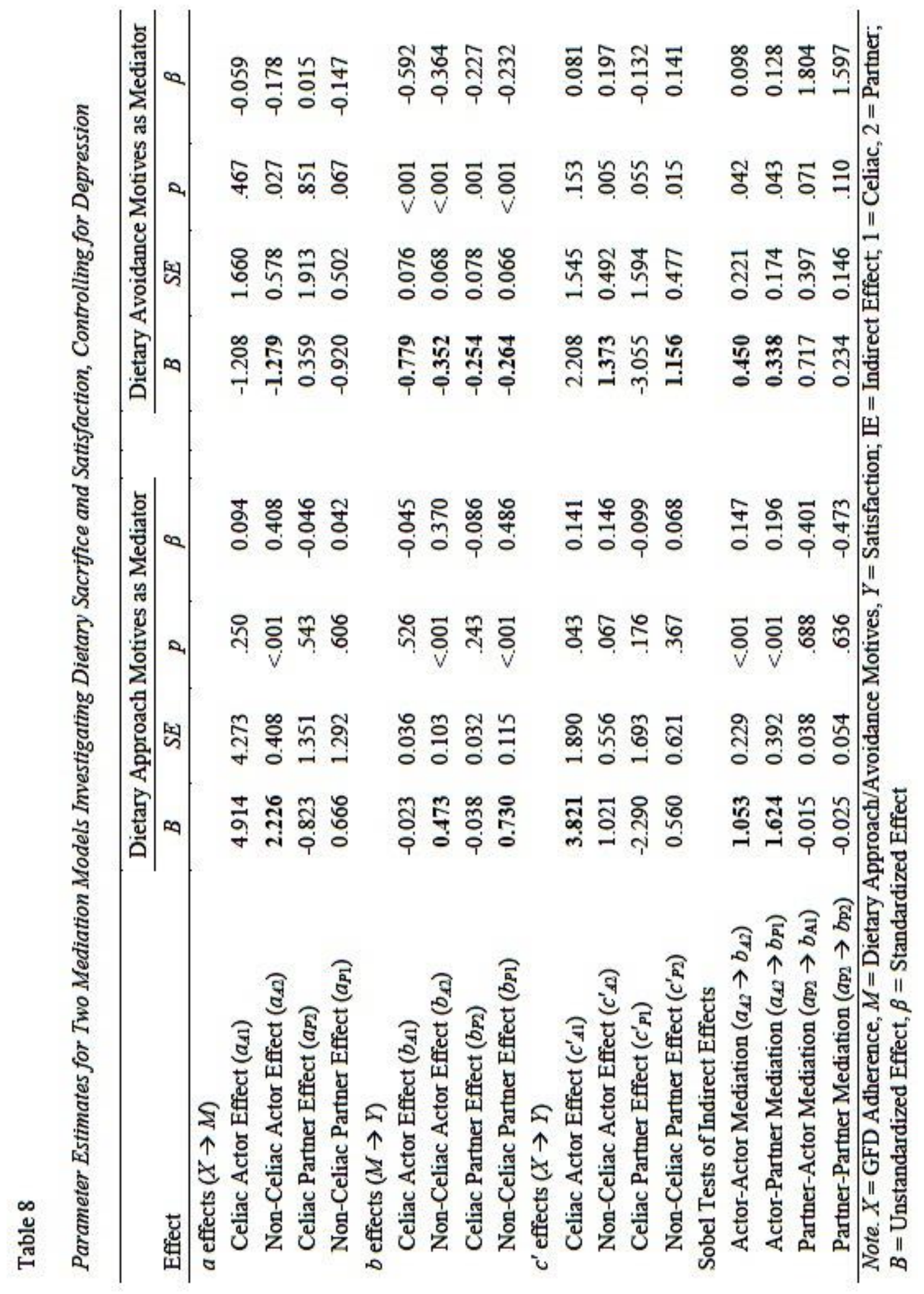




\section{References}

Ainsworth, M.D. (1969). Object relations, dependency, and attachment: A theoretical overview of the infant-mother relationship. Child Development, 40(4), 969-1025.

Alaedini, A., \& Green, P.H.R. (2005). Narrative review: Celiac disease: Understanding a complex autoimmune disorder. Annals of Internal Medicine, 142, 289-298.

Amiraian, D., \& Sobal, J. (2009). Dating and eating: How university students select eating settings. Appetite, 52, 226-229.

Anderson, J.W., \& Gustafson, N.J. (1989). Adherence to high-carbohydrate, high-fiber diets. The Diabetes Educator, 15(5), 429-434.

Andreyeva, T., Sturm, R., \& Ringel, J.S. (2004). Moderate and severe obesity have large differences in health care costs. Obesity, 12(12), 1936-1943.

Barelds, D.H.P., \& Barelds-Dijkstra, P. (2010). Humor in intimate relationships: Ties among sense of humor, similarity in humor and relationship quality. Humor: International Journal of Humor Research, 23(4), 447-465.

Baron, R.M., \& Kenny, D.A. (1986). The moderator-mediator variable distinction in social psychological research: Conceptual, strategic, and statistical considerations. Journal of Personality and Social Psychology, 51(6), 1173-1182.

Beach, S.R.H., Martin, J.K., Blum, T.C., \& Roman, P.M. (1993). Effects of marital and co-worker relationships on negative affect: Testing the central role of marriage. American Journal of Family Therapy, 21, 313-323. 
Blair, S.L., \& Johnson, M.P. (1992). Wives' perceptions of the fairness of division of household labor: The intersection of housework and ideology. Journal of Marriage and Family, 54(3), 570-581.

Bove, C.F., Sobal, J., \& Rauschenbach, B.S. (2003). Food choices among newly married couples: Convergence, conflict, individualism, and projects. Appetite, 40, 25-41.

Burleson, B.R. (2003). The experience and effects of emotional support: What the study of cultural and gender differences can tell us about close relationships, emotion, and interpersonal communication. Personal Relationships, 10, 1-23.

Bushara, K.O. (2008). Neurologic presentation of Celiac disease. Gastroenterology, 128, 592-597.

Butterfield, R.M., \& Lewis, M.A. (2002). Health-relatd social influence: A social ecological perspective on tactic use. Journal of Social and Personal Relationships, 19, 505-526.

Carver, C. S. (1997). You want to measure coping but your protocol's too long: Consider the Brief COPE. International Journal of Behavioral Medicine, 4, 92-100.

Catassi, C., Bearzi, I., \& Holmes, G.K. (2005). Association of Celiac disease and intestinal lymphomas and other cancers. Gastroenterology, 128(4), S79-S86.

Center for Disease Control and Prevention. (2011). National Diabetes Fact Sheet. National Center for Chronic Disease Prevention and Health Promotion, Division of Diabetes Translation. Retrieved from: http://www.cdc.gov/diabetes/pubs/pdf/ndfs_2011.pdf 
Cheung, M.W.L. (2007). Comparison of approaches to constructing confidence intervals for mediating effects using Structural Equation Models. Structural Equation Modeling, 14, 227-246.

Coats, E.J., Janoff-Bulman, R., \& Alpert, N. (1996). Approach versus avoidance goals: Differences in self-evaluation and well-being. Personality and Social Psychology Bulletin, 22, 1057-1067.

Cohen, J., \& Manning, W. (2010). The relationship context of premarital serial cohabitation. Social Science Research, 39, 766-776.

Cohen, S. (1988). Psychological models of the role of social support in the etiology of physical disease. Health Psychology, 7, 269-297.

Cohen, S., \& Hoberman, H. (1983). Positive events and social supports as buffers of life change stress. Journal of Applied Social Psychology, 13, 99-125.

Collin, P., Reunala, T., Pukkala, E., Laippala, P., Keyriläinen, O., \& Pasternack, A. (1994). Coeliac disease: Associated disorders and survival. Gut, 35, 1215-1218.

Copelton, D.A., \& Valle, G. (2009). "You don't need a prescription to go gluten-free": The scientific self-diagnosis of Celiac disease. Social Science \& Medicine, 69, 623-631.

Craig, P. L., \& Truswell, A. S. (1988). Dynamics of food habits of newly married couples: Food related activities and attitudes towards food. Journal of Human Nutrition and Dietetics, 1, 401-412. 
Craig, P. L., \& Truswell, A. S. (1994). Dynamics of food habits of newly married couples: Who makes changes in the foods consumed? Journal of Human Nutrition and Dietetics, 7, 347-361.

Cutrona, C.E. (1996). Social support in couples: Marriage as a resource in times of stress. Thousand Oaks, CA: Sage.

Cutrona, C.E. (1998). Social support as a determinant of marital quality: The interplay of negative and supportive behaviors. In G.R. Pierce, B.R. Sarason, and I.G. Sarason (Eds.), Handbook of Social Support and the Family (pp. 173-194). New York: Plenum Press.

DeMaris, A. (2007). The role of relationship inequity in marital disruption. Journal of Social and Personal Relationships, 24(2), 177-195.

Devine, C., Connors, M., Sobal, J., \& Bisogni, C. (2003). Sandwiching it in: Managing food and work in low and moderate-income urban households Social Science \& Medicine, 56, 617-630.

Diener, E., \& Oishi, S. (2005). The nonobvious social psychology of happiness. Psychological Inquiry, 16(4), 162-167.

DiMatteo, M.R. (2004). Social support and patient adherence to medical treatment: A meta-analysis. Health Psychology, 23(2), 207-218.

Elliot, A.J., \& Sheldon, K.M. (1997). Avoidance achievement motivation: A personal goals analysis. Journal of Personality and Social Psychology, 73, 171-185.

Farrel, R.J., \& Kelly, C.P. (2002). Celiac Sprue. The New England Journal of Medicine, 346(3), 180-188. 
Fasano, A., Berti, I., Gerarduzzi, T., Not, T., Colletti, R.B., Drago, S., Elitsur, Y., Green, P.H.R., Guandalini, S., Hill, I.D., Pietzak, M., Ventura, A., Thorpe, M., Kryszak, D., Fornaroli, F., Wasserman, S.S., Murray, J.A., \& Horvath, K. (2003). Prevalence of Celiac disease in at-risk and not-at-risk groups in the United States. Archives of Internal Medicine, 163, 286-292.

Fasano, A., \& Catassi, C. (2012). Celiac Disease. The New England Journal of Medicine, $367,2419-2426$.

Franks, M.M., Sahin, Z.S., Seidel, A.J., Shields, C.G., Oates, S.K., \& Boushey, C.J. (2012). Table for two: Diabetes distress and diet-related interactions of married patients with diabetes and their spouses. Families, Systems, \& Health, 30(2), 154165.

Frissora, C.L., \& Koch, K.L. (2005). Symptom overlap and comorbidity of irritable bowel syndrome with other conditions. Current Gastroenterology Reports, 7, 264271.

Fritz, H.L., \& Helgeson, V.S. (1998). Distinctions of unmitigated communion from communion: Self-neglect and overinvolvement with others. Journal of Personality and Social Psychology, 75, 121-140.

Gable, S.L. (2006). Approach and avoidance social motives and goals. Journal of Personality, 74, 175-222.

Gable, S.L., Reis, H.T., \& Elliot, A.J. (2000). Behavioral activation and inhibition in everyday life. Journal of Personality and Social Psychology, 78, 1135-1149. 
Gottman, J.M. (1994). What predicts divorce? The relationship between marital processes and marital outcomes. Hillsdale, NJ: Lawrence Erlbaum Associates, Inc.

Gove, W.R. (1979). Sex, marital status, and mortality. American Journal of Sociology, $79,45-67$.

Gray, J. (1987). The Psychology of Fear and Stress (2 ${ }^{\text {nd }}$ ed.). New York, NY: Cambridge. Green, P.H.R. (2005). The many faces of Celiac disease: Clinical presentation of Celiac Disease in the adult population. Gastroenterology, 128, 74-78.

Green, P.H.R., Stavropoulos, S.N., Panagi, S.G., Goldstein, S.L., McMahon, D.J., Absan, H., \& Neugut, A.I. (2001). Characteristics of adult Celiac Disease in the USA: Results of a national survey. The American Journal of Gastroenterology, 96(1), 126-131.

Hallert, C., Granno, C., Grant, C., Hulten, S., Midhagen, G., Strom, M., Svensson, H., Valdimarsson, T., \& Wickstrom, T. (1998). Quality of life of adult coeliac patients treated for 10 years. Scandinavian Journal of Gastroenterology, 33, 933938.

Hallert, H.C., Granno, C., Hulten, S., Midhagen, G., Strom, M., Svensson, H., \& Valdimarsson, T. (2002). Living with coeliac disease: Controlled study of burden of illness. Scandinavian Journal of Gastroenterology, 37, 39-42.

Haupt, A. (2012, April). Is a gluten-free diet smart for weight loss? US News: Health. Retrieved from: http://health.usnews.com/health-news/articles/2012/04/11/is-agluten-free-diet-smart-for-weight-loss. 
DIETARY SACRIFICE IN CELIAC RELATIONSHIPS

Hoffenberg, E.J., MacKenzie, T., Barriga, K.J., Eisenbarth, G.S., Haas, J.E., Erlich, H., Bugawan, T.L., Sokol, R.J., Taki, I., Norris, J.M., \& Rewers, M. (2003). A prospective study of the incidence of childhood Celiac Disease. Journal of Pediatric Medicine, 143, 308-314.

Hornell, A. (2008). Living well with Celiac disease? Journal of Pediatric Gastroenterology and Nutrition, 47, 544-546.

Impett E.A., \& Gordon A.M. (2008). For the good of others: Toward a positive psychology of sacrifice. In Lopez S.J. (Ed.), Positive Psychology: Exploring the Best in People (pp. 79-100). Westport, CT: Greenwood.

Impett, E.A., \& Gordon, A.M. (2010). Why do people sacrifice to approach rewards versus to avoid costs? Insights from attachment theory. Personal Relationships, $17,299-315$.

Impett, E.A., \& Peplau, L.A. (2002). Why some women consent to unwanted sex with a dating partner: Insights from attachment theory. Psychology of Women Quarterly, 26, 359-369.

Impett, E.A., Gable, S.L., \& Peplau, L.A. (2005). Giving up and giving in: The costs and benefits of daily sacrifice in intimate relationships. Journal of Personality and Social Psychology, 89(3), 327-344.

Impett, E.A., Gordon, A.M., Kogan, A., Oveis, C., Gable, S.L., \& Keltner, D. (2010). Moving toward more perfect unions: Daily and long-term consequences of approach and avoidance goals in romantic relationships. Journal of Personality and Social Psychology, 99(6), 948-963. 
Impett, E.A., Peplau, L.A., \& Gable, S.L. (2005). Approach and avoidance sexual motivation: Implications for personal and interpersonal well-being. Personal Relationships, 12, 465-482.

Impett, E.A., Strachman, A., Finkel, E.J., \& Gable, S.L. (2008). Maintaining sexual desire in intimate relationships: The importance of approach goals. Journal of Personality and Social Psychology, 94, 808-823.

Joseph, S., Linley, P.A., Harwood, J., Lewis, C.A., \& McCollam, P. (2004). Rapid assessment of well-being: The Short Depression-Happiness Scale (SDHS). Psychology and Psychotherapy: Theory, Research, and Practice, 77, 1-14.

Kashy, D.A., \& Kenny, D.A. (1999). The analysis of data from dyads and groups. In H.T. Reis \& C.M. Judd (Eds.), Handbook of Research Methods in Social Psychology (pp. 451-477). New York: Cambridge University Press.

Kelley, H.H. (1979). Personal Relationships: Their Structures and Processes. Hillsdale, NJ: Lawrence Erlbaum.

Kelley, H.H., \& Thibaut, J.W. (1978). Interpersonal Relations: A Theory of Interdependence. New York: Wiley.

Kelley, H.H., Bercheid, E., Christensen, A., Harvey, J.H. \& Huston, T.L. (1983). Close Relationships. New York: W.H. Freeman \& Co.

Kemmer, D., Anderson, A.S., \& Marshall, D.W. (1998). Living together and eating together: Changes in food choice and eating habits during the transition from single to married/cohabitating. Sociological Review, 46(1), 48-72. 
Kenny, D.A., \& Cook, W.L. (1999). Partner effects in relationship research: Conceptual issues, analytic difficulties, and illustrations. Personal Relationships, 6, 433-448.

Kenny, D.A., Kashy, D.A., \& Cook, W.L. (2006). Dyadic Data Analysis. New York: The Guilford Press.

Kiecolt-Glaser, J.K., \& Newton, T.L. (2001). Marriage and health: His and hers. Psychological Bulletin, 127, 472-503.

Kogan, A., Impett, E.A., Oveis, C., Hui, B., Gordon, A.M., \& Keltner, D. (2010). When giving feels good: The intrinsic benefits of sacrifice in romantic relationships for the communally motivated. Psychological Science, 21, 1918-1923.

Lebwohl, B., Tennyson, C.A., Holub, J.L., Lieberman, D.A., Neugut, A.I., \& Green, P.H.R. (2012). Gender and racial disparities in duodenal biopsy to evaluate for Celiac Disease. Gastrointestinal Endoscopy, 76(4), 779-785.

Ledermann, T., \& Macho, S. (2009). Mediation in dyadic data at the level of the dyads: A Structural Equation Modeling approach. Journal of Family Psychology, 23, 661670.

Ledermann, T., Macho, S., \& Kenny, D.A. (2011). Assessing mediation in dyadic data using the Actor-Partner Interdependence Model. Structural Equation Modeling: A Multidisciplinary Journal, 18(4), 595-612.

Leffler, D.A., Dennis, M., Edwards George, J.B. Jamma, S., Maggie, S., Cook, E.F., Schuppan, D., \& Kelly, C.P. (2009). A simple validated gluten-free diet adherence survey for adults with Celiac disease. Clinical Gastroenterology and Hepatology, 7, 530-536. 
Leffler, D.A., Edwards-George, J., Dennis, M., Schuppan, D., Cook, F., Franko, D.L., Blom-Hoffman, J., \& Kelly, C.P. (2008). Factors that influence adherence to a gluten-free diet in adults with Celiac disease. Digestive Diseases and Sciences, 53(6), 1573-1581.

Lewis, M.A., McBride, C.M., Pollak, K.I., Puleo, E., Butterfield, R.M., \& Emmons, K.M. (2006). Understanding health behavior change among couples: An interdependence and communal coping approach. Social Science \& Medicine, 62, 1369-1380.

Lichter, D.T., Turner, R.N., \& Sassler, S. (2010). National estimates of the rise in serial cohabitation. Social Science Research, 39, 754-765.

Louk, K.R., Schafer, E., Schafer, R.B., \& Keith, P. (1999). Comparison of dietary intakes of husbands and wives. Journal of Nutrition Education, 31(3), 145-153.

Markey, C.N., Markey, P.M., \& Birch, L.L. (2001). Interpersonal predictors of dieting practices among married couples. Journal of Family Psychology, 15(3), 464-475.

Markey, C.N., Markey, P.M., \& Gray, H.F. (2007). Romantic relationships and health: An examination of individuals' perceptions of their romantic partners' influences on their health. Sex Roles, 57, 435-445.

Markey, C.N., Markey, P.M., Schneider, C., \& Brownlee, S. (2005). Marital status and health beliefs: Different relations for men and women. Sex Roles: A Journal of Research, 53, 443-451. 
Mattingly, B.A., \& Clark, E.M. (2012). Weakening relationships we try to preserve: Motivated sacrifice, attachment, and relationship quality. Journal of Applied Social Psychology, 42(2), 373-386.

Meichenbaum, D. (1985). Stress Inoculation Training. New York, NY: Pergamon.

Molero, F., Shaver, P.R., Ferrer, E., Cuadrado, I., \& Alonso-Arbiol, I. (2011). Attachment insecurities and interpersonal processes in Spanish couples: A dyadic approach. Personal Relationships, 18(4), 617-629.

Myers, J. L. (1979). Fundamentals of Experimental Design (3rd ed.). Boston: Allyn \& Bacon.

Neff, L.A., \& Broady, E.F. (2011). Stress resilience in early marriage: Can practice make perfect?. Journal of Personality and Social Psychology, 101(5), 1050-1067.

Nelson, C.C., Sapp, A., Berkman, L.F., Li, Y., \& Sorenson, G. (2011). Allocation of household responsibilities influences change in dietary behavior. Social Science \& Medicine, 73, 1517-1524.

Niewinski, M.M. (2008). Advances in Celiac disease and the gluten-free diet. Journal of the American Dietetics Association, 108, 661-672.

Noller, P. (1996). What is this thing called love? Defining the love that supports marriage and family. Personal Relationships, 3, 97-115.

Not, T., Horvath, K., Hill, I.D., Partanen, J., Hammed, A., Magazzu, G., \& Fasano, A. (1998). Celiac Disease risk in the USA: High prevalence of antiendomysium antibodies in healthy blood donors. Scandinavian Journal of Gastroenterology, 33(5), 494-498. 
Osborne, J.W. \& Overbay, A. (2004). The power of outliers (and why researchers should always check for them). Practical Assessment, Research \& Evaluation, 9(6).

Pachucki, M.A., Jacques, P.F., \& Christakis, N.A. (2011). Social network concordance in food choice among spouses, friends, and siblings. American Journal of Public Health, 101(11), 2170-2177.

Paisley, J., Beanlands, H., Goldman, J., Evers, S., \& Chappell, J. (2008). Dietary change: What are the responses and roles of significant others? Journal of Nutrition Education and Behavior, 40, 80-88.

Pasch, L.A., Bradbury, T.N. \& Davila, J. (1997). Gender, negative affectivity, and observed social support behavior in marital interaction. Personal Relationships, 4 , 361-378.

Patterson, T., Sallis, J., Nader, P., Kaplan, R., Rupp, J., Atkins, C., \& Senn, K. (1989). Familial similarities of change in cognitive, behavioral, and physiological variables in a cardiovascular health promotion program. Journal of Pediatric Psychology, 14, 277-292.

Perry-Jenkins, M., Newkirk, K., \& Ghunney, A.K. (2013). Family work through time and space: An ecological perspective. Journal of Family Theory \& Review, 5, 105123.

Rappoport, L. (2003). How we eat: Appetite, culture, and the psychology of food. Totonto, Ontario: ECW Press.

Reed, R.G., Butler, E.A., \& Kenny, D.A. (2013). Dyadic models for the study of health. Social \& Personality Psychology Compass, 7(4), 228-245. 
Revenson, T.A., Kayser, K., \& Bodenmann, G. (2005). Couples Coping with Stress: Emerging Perspectives on Dyadic Coping. Washington, D.C.: American Psychological Association.

Ristovski-Slijepcevic, S., \& Chapman, G.E. (2005). Integration and individuality in healthy eating: Meanings, values, and approaches of childless, dual earner couples. Journal of Human Nutrition \& Dietetics, 18(4), 301-309.

Robles, T.F., \& Kiecolt-Glaser, J.K. (2003). The physiology of marriage: Pathways to health. Physiology \& Behavior, 79, 409-416.

Rowe, L.S., Doss, B.D., Hsueh, A.C., Libet, J., \& Mitchell, A.E. (2011). Coexisting difficulties and couple therapy outcomes: Psychopathology and intimate partner violence. Journal of Family Psychology, 25(3), 455-458.

Ruppel, E.K., \& Curran, M.A. (2012). Relational sacrifices in romantic relationships: Satisfaction and the moderating role of attachment. Journal of Social and Personal Relationships, 29(4), 508-529.

Rusbult, C.E., \& Buunk, B.P. (1993). Commitment processes in close relationships: An interdependence analysis. Journal of Social and Personal Relationships, 10, 175204.

Rusbult, C.E., \& Van Lange, P.A.M. (2003). Interdependence, Interaction, and Relationships. Annual Review of Psychology, 54, 351-375.

Rusbult, C.E., Martz, J.M., \& Agnew, C.R. (1998). The Investment Model Scale: Measuring commitment level, satisfaction level, quality of alternatives, and investment size. Personal Relationships, 5, 357-391. 
Ryden, P.J., \& Sydner, Y.M. (2011). Implementing and sustaining dietary change in the context of social relationships. Scandinavian Journal of Caring Sciences, 25, 583590.

Ryff, C.D., \& Singer, B. (2000). Interpersonal flourishing: A positive health agenda for the new millennium. Personality and Social Psychology Review, 4(1), 30-44.

Sainsbury, K., \& Mullan, B. (2011). Measuring beliefs about gluten free diet adherence in adult coeliac disease using the theory of planned behavior. Appetite, 56, 476483.

Schaefer, M. T., \& Olson, D. H. (1981). Diagnosing intimacy: The PAIR Inventory. Journal of Marital and Family Therapy, 7, 47-60.

Schwarzer, R. \& Leppin, A. (1991). Social support and health: A theoretical and empirical overview. Journal of Social and Personal Relationships, 8(1), 99-127.

Shah, S., \& Leffler, D. (2010). Celiac disease: An underappreciated issue in women's health. Journal of Women's Health, 6(5), 1-14.

Sobal, J., \& Nelson, M.K. (2003). Commensal eating patterns: A community study. Appetite, 41, 181-190.

Sobel, M.E. (1982). Asymptotic confidence intervals for Indirect Effects in Structural Equation Models. Sociological Methodology, 13, 290-312.

Sverker, A., Hensing, G., \& Hallert, C. (2005). Controlled by food - lived experiences of coeliac disease. Journal of Human Nutrition and Dietetics, 18, 171-180. 
Sverker, A., Ostlund, G., Hallert, C., \& Hensing, G. (2009). 'I lose all these hours...' Exploring gender and consequences of dilemmas experienced in everyday life with coeliac disease. Scandinavian Journal of Caring Sciences, 23, 342-352.

Swann, W.B. (1983). Self-verification: Bringing social reality into harmony with the self. In J. Suls \& A.G. Greenwald (Eds.), Psychological Perspectives on the Self (Vol. 2, pp. 33-66), Hillsdale, NJ: Erlbaum.

Tabachnick, B.G., \& Fidell, L.S. (2007). Using Multivariate Statistics ( ${ }^{\text {th }}$ edition). Pearson Education, Inc.

Tack, G.J., Verbeek, W.H.M., Schreurs, M.W.J., \& Mulder, C.J.J. (2010). The spectrum of Celiac Disease : Epidemiology, clinical aspects and treatment. National Review of Gastroenterology and Hepatology, 7, 204-213.

Tang, C-Y. \& Curran, M.A. (2012). Marital commitment and perceptions of fairness in household chores. Journal of Family Issues, 34(12), 1598-1622.

Thibaut, J.W., \& Kelley, H.H. (1959). The Social Psychology of Groups. New York: Wiley.

Trief, P.M., Sandberg, J., Greenberg, R.P., Graff, K., Castronova, N., Yoon, M., \& Weinstock, R.S. (2003). Describing support: A qualitative study of couples living with diabetes. Families, Systems \& Health, 21(1), 57-67.

Tucker, J.S., Friedman, H.S., Wingard, D.L., \& Schwartz, J.E. (1996). Marital history at midlife as a predictor of longevity: Alternative explanations to the protective effect of marriage. Health Psychology, 15, 94-101. 
Umberson, D. (1992). Gender, marital status and the social control of health behavior. Social Science and Medicine, 34, 907-917.

Umberson, D., \& Montez, J.K. (2010). Social relationships and health: A flashpoint for health policy. Journal of Health and Social Behavior, 51, S54-S66.

Umberson, D., Williams, K., Powers, D.A., Liu, H., \& Needham, B. (2006). You make me sick: Marital quality and health over the life course. Journal of health and social behavior, 47, 1-16.

Van Lange, P.A.M., Agnew, C.R., Harinck, F., \& Steemers, G.E.M. (1997a). From game theory to real life: How social value orientation affects willingness to sacrifice in ongoing close relationships. Journal of Personality and Social Psychology, 73(6), $1330-1344$.

Van Lange, P.A.M., Rusbult, C.E., Drigotas, S.M., Arriaga, X.B., Witcher, B.S., \& Cox, C.L. (1997b). Willingness to sacrifice in close relationships. Journal of Personality and Social Psychology, 72(6), 1373-1395.

Veen, M., te Molder, H., Gremmen, B., \& Van Woerkum, C. (2010). Quitting is not an option: An analysis of online diet talk between Celiac disease patients. Health, 14, $23-40$.

Vitaliano, P.P., Young, H.M. Russo, J., Romano, J., \& Magana-Amato, A. (1993). Does expressed emotion in spouses predict subsequent problems among care recipients with Alzheimer's disease? Journal of Gerontology, 48, P202-P209.

Voelker, R. (2012). Escalating obesity rates pose health, budget threats. Journal of the American Medical Association, 308(15), 1514. 
Wallis, D.J., \& Hetherington, M.M. (2009). Emotions and eating. Self-reported and experimentally induced changes in food intake under stress. Appetite, 52, 355362.

Wansink, B., Cheney, M.M., \& Chan, N. (2003). Comfort food preferences across age and gender. Physiology \& Behavior, 79, 739-747.

Wickham, R.E., \& Knee, C.R. (2012). Interdependence theory and the Actor-Partner Interdependence Model: Where theory and method converge. Personality and Social Psychology Review, 16(4), 375-393.

Wieselquist, J., Rusbult, C.E., Foster, C.A., \& Agnew, C.R. (1999). Commitment, prorelationship behavior, and trust in close relationships. Journal of Personality and Social Psychology, 77(5), 942-966.

Wilson, S.E. (2001). Socioeconomic status and the prevalence of health problems among married couples in late midlife. American Journal of Public Health, 91, 131-135.

Wood, J.T. (1993). Engendered relations: Interaction, caring, power, and responsibility in intimacy. In S. Duck (Ed.), Social Context and Relationships (pp. 26-54). Newbury Park, CA: Sage.

Zardakas, M., Cranney, A., Case, S., Molloy, M., Switzer, C., Graham, D, Butzner, J.D., Rashid, M., Warren, R.E., \& Burrows, V. (2006). The impact of a gluten-free diet on adults with coeliac disease: results of a national survey. Journal of Human Nutrition and Dietetics, 19, 41-49. 


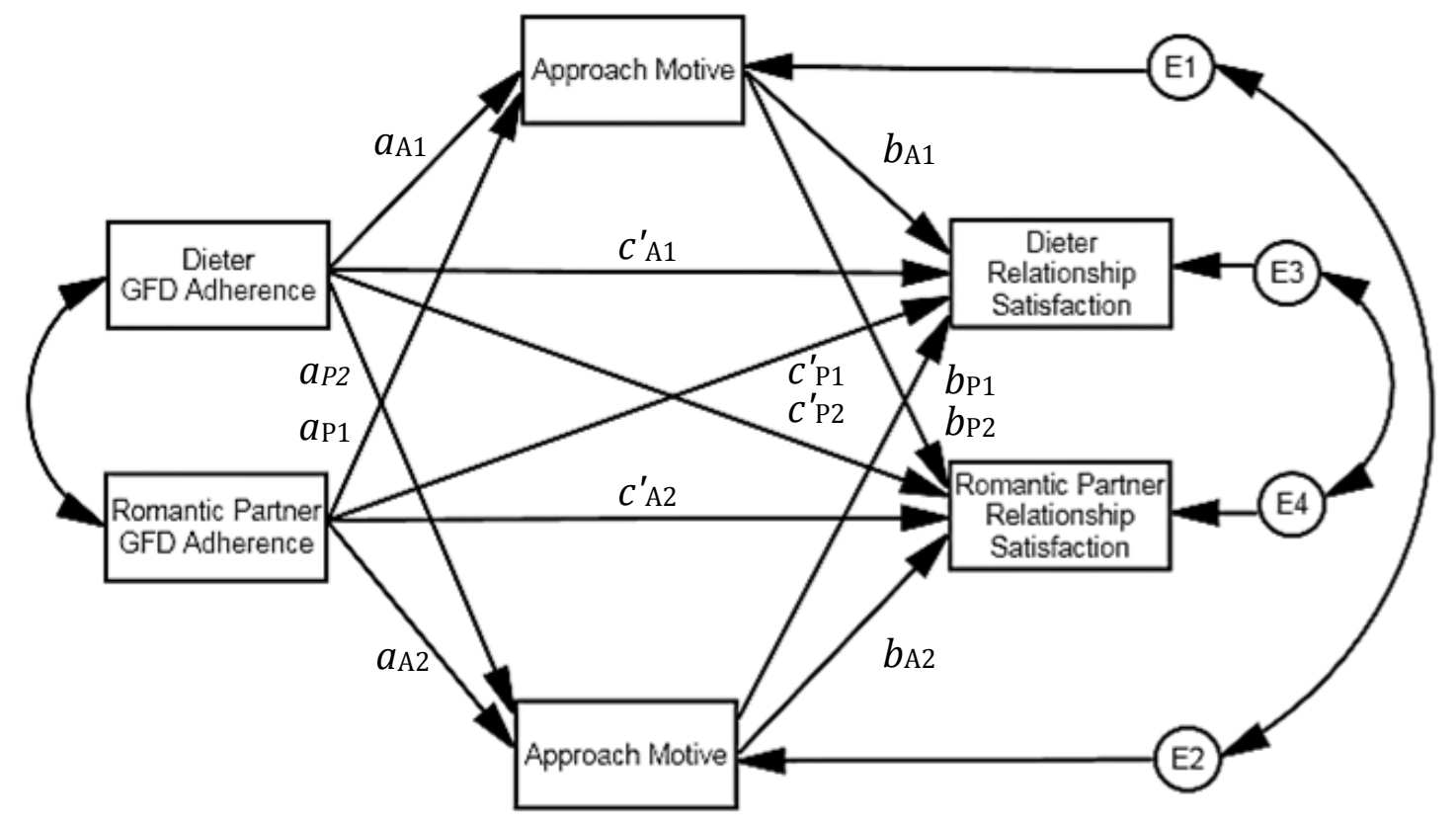

Figure 1. Example of Fully Saturated APIMeM with Labeled Parameters 


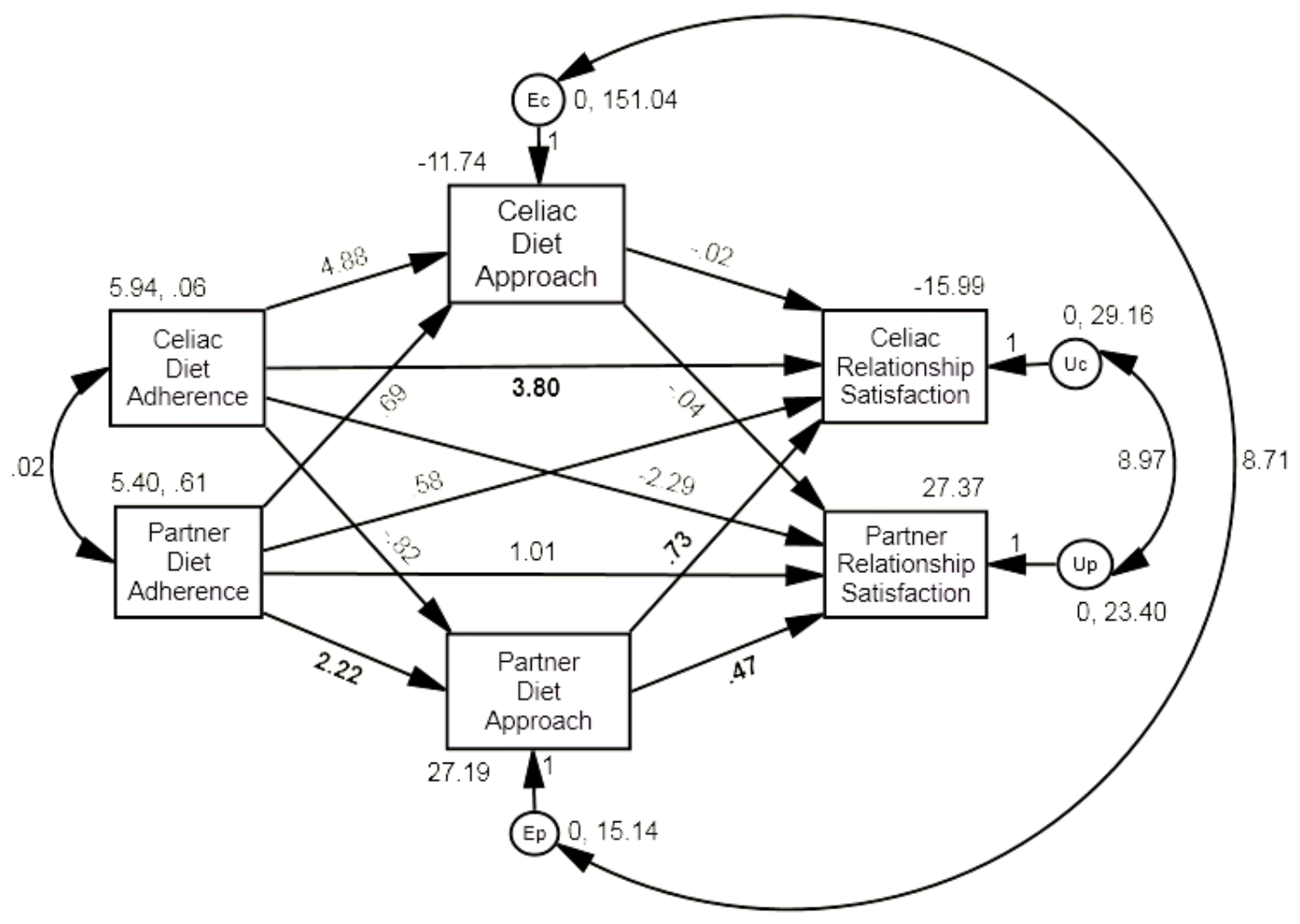

Figure 2. Saturated APIMeM with Dietary Approach Motives as the Mediator 


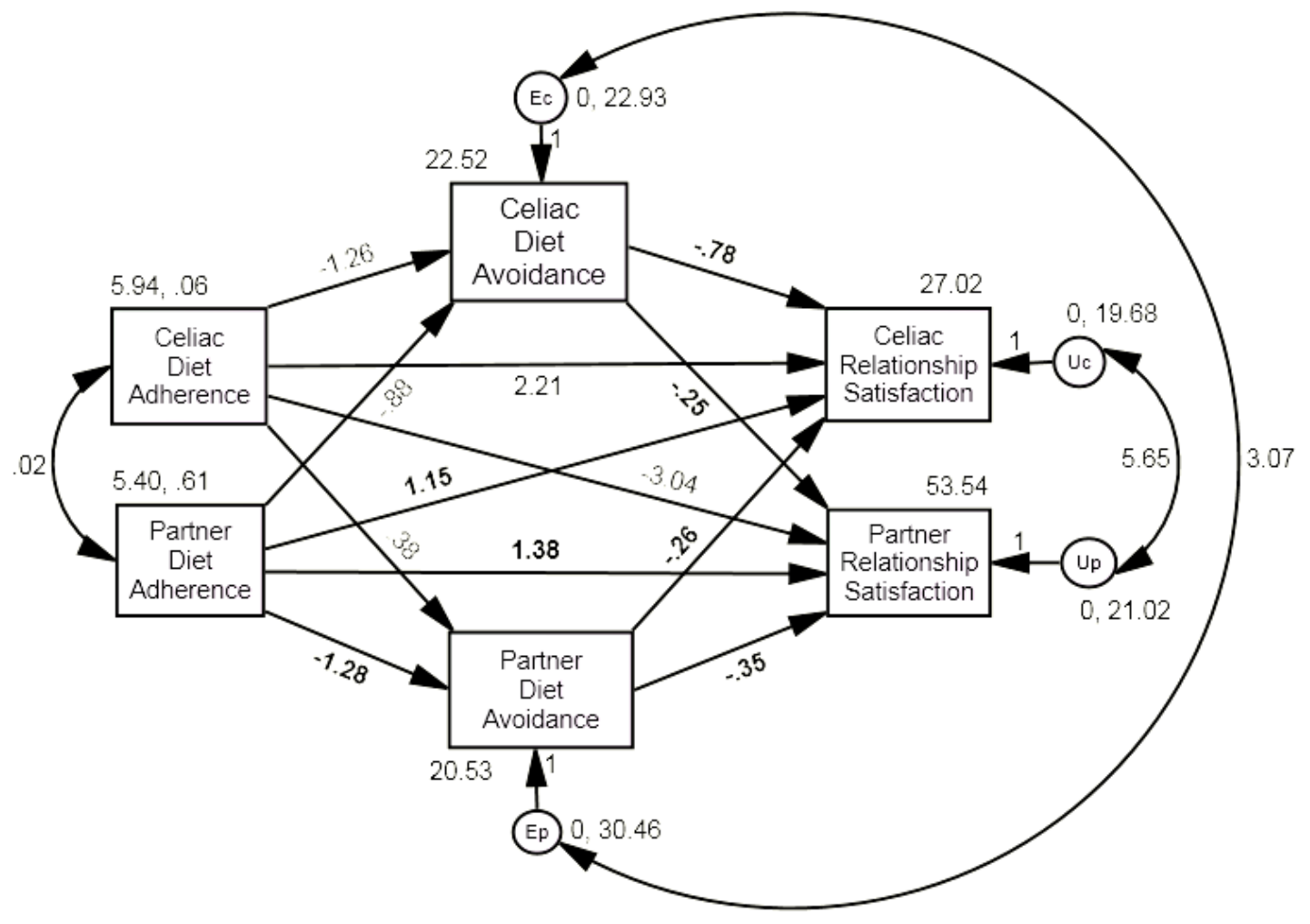

Figure 3. Saturated APIMeM with Dietary Avoidance Motives as the Mediator 


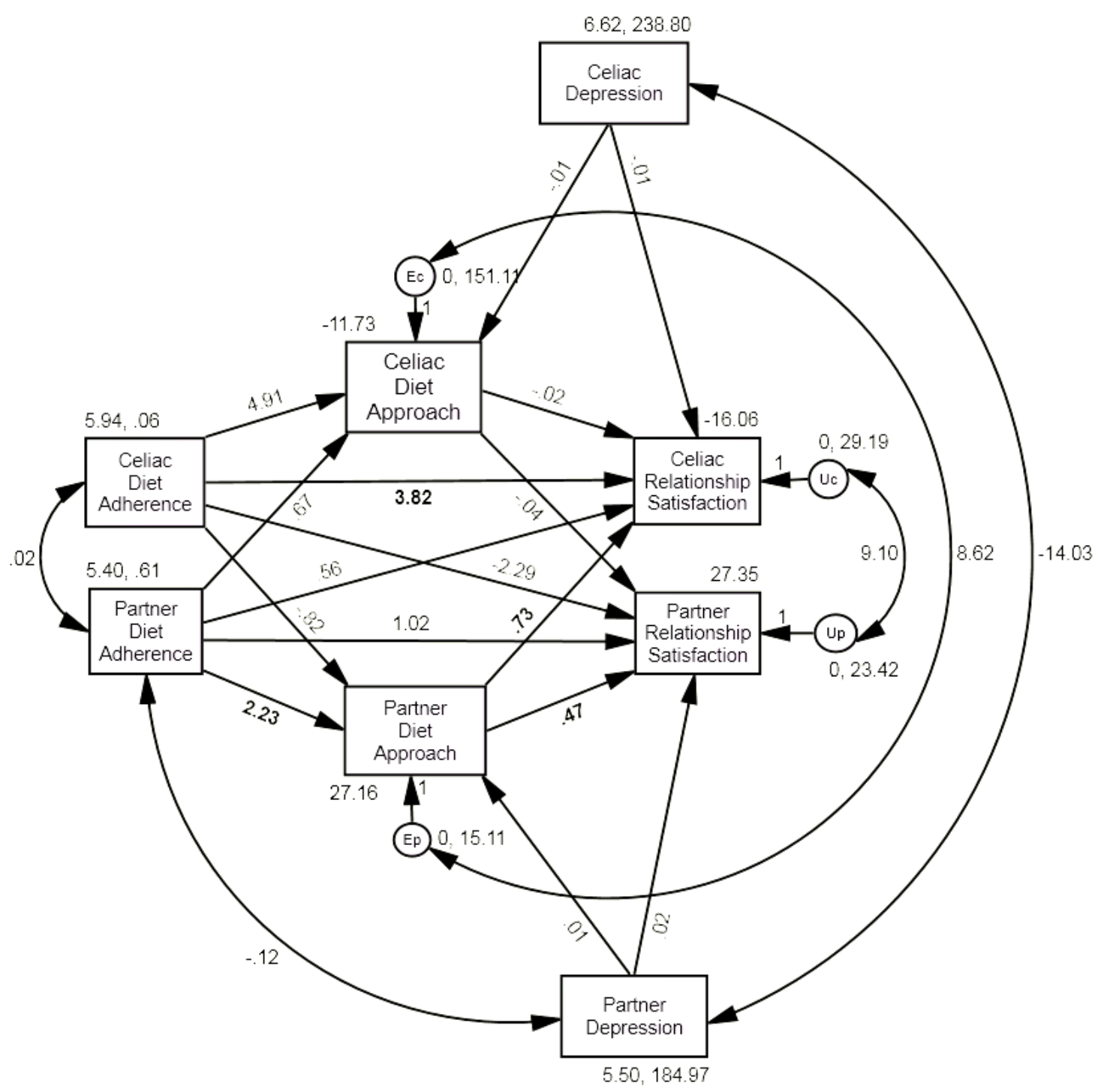

Figure 4. APIMeM with Dietary Approach Motives, Controlling for Depression 


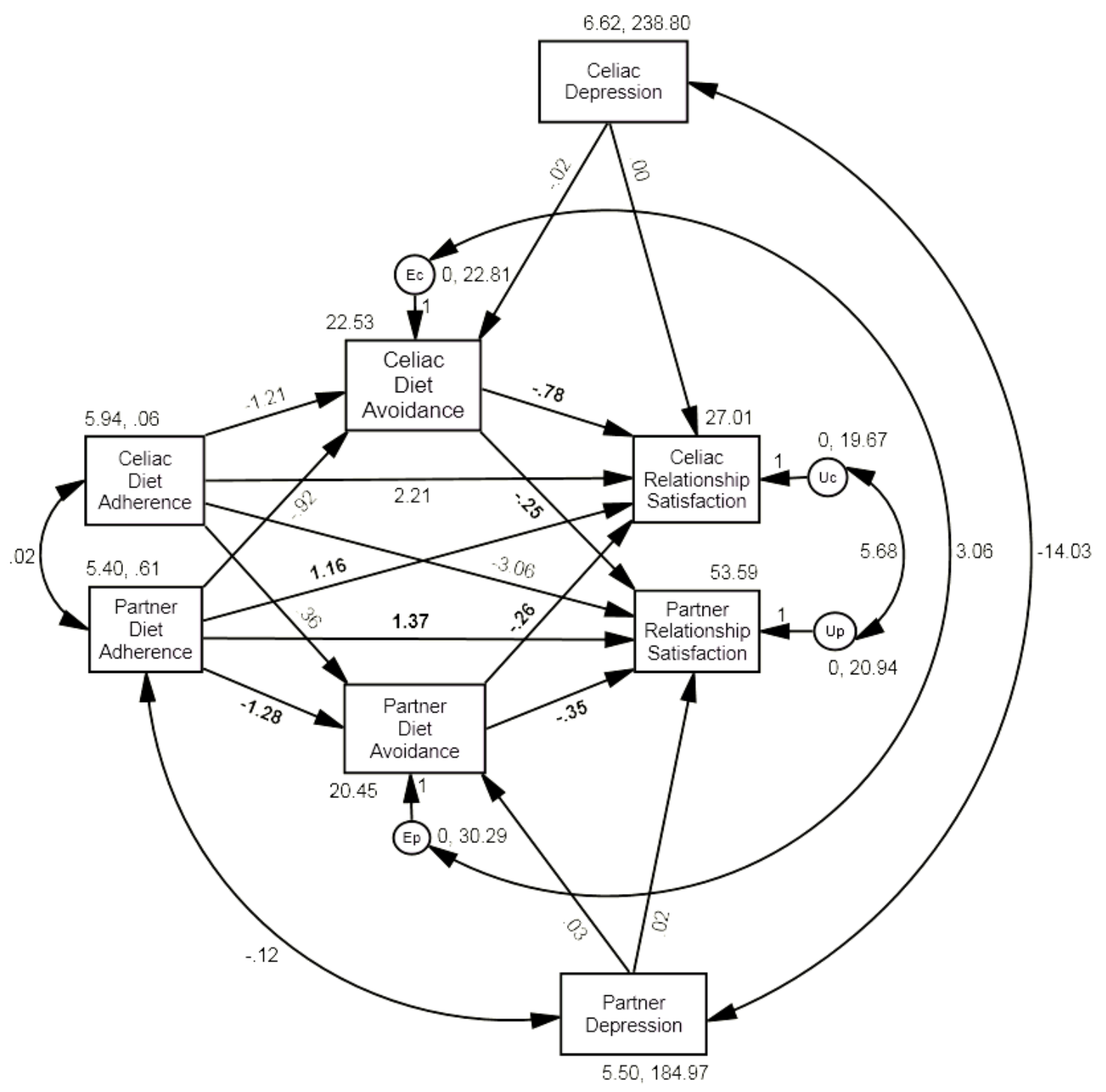

Figure 5. APIMeM with Dietary Avoidance Motives, Controlling for Depression 
Appendix A

Study Advertisements

Web Advertisement:

\section{Adults with Celiac disease and their significant others are needed for a research study!}

People with Celiac are needed to participate in a nationwide survey. Questions will focus on how you eat, what your relationship is like, and your thoughts about the gluten free diet. Both medical- and self-diagnosed people with Celiac can take this survey.

If you choose to take the survey, we will also contact your significant other or spouse by email to see if he or she would like to take it. Specifically, we are looking for couples that have been together for at least six months, and where both members are at least 18 years old.

The survey will take about 20 to 30 minutes to complete. Participation is voluntary, meaning you can decide to quit at any time. You and your significant other are encouraged to take the survey separate from each other to maintain confidentiality.

To take this survey, visit this link:

https://portlandstate.qualtrics.com//SE/?SID=SV_erDIIMjARHztrPn

Twitter Advertisement:

Adults with Celiac disease and their significant others needed for a nationwide survey! Click the link to learn more:

https://portlandstate.qualtrics.com//SE/?SID=SV_erD1IMjARHztrPn 


\section{Appendix B \\ Statement of Informed Consent \\ Study of Dieting Behaviors and Romantic Relationships}

You are invited to participate in a research study conducted by Dr. Cynthia Mohr and Lindsey Alley from the Department of Psychology at Portland State University (PSU). The researchers are interested in the diets of couples where at least one member has Celiac disease and the types of interactions between both partners. The results of this study will be used to understand more about the eating behaviors and relationships of individuals with Celiac. To participate, you and your significant other will need to be at least 18 years of age, and in a committed relationship of at least six months. Also, either you or your partner (or both) must be self- or medically-diagnosed with Celiac disease.

\section{What will I have to do?}

If you decide to participate, you will enter your and your significant other's email address and birthdates on the next page. Once you have completed this step, you will fill out an online survey. You will answer questions about your relationship, your feelings, and your diet. The survey will take about 20 to 30 minutes to finish.

We will use your significant other's email address to invite them to take the survey as well. Their participation, like yours, will be voluntary. If both of you participate, your birthdates will be used to match your surveys together. This information will be deleted after they have been matched. You are not required to share your answers with your partner, and they should not feel pressured to share their answers with you. All of your responses will be kept completely confidential.

\section{Are there any risks?}

There is no direct cost to you for participating in this study. There are no expected physical or psychological risks from participating in this study, aside from the brief interruption in time to complete the survey. It is possible that some of the questions may lead you to recall unpleasant feelings, which could be upsetting. You are welcome to skip any of these questions with no penalty to you.

\section{Your participation is voluntary.}

Your participation in this study is completely voluntary. You and/or your partner are under no obligation to participate and choosing not to participate will not affect your relationship with Portland State University. You may choose not to answer questions or quit participating in this study at any time.

\section{What will I get in return?}

The results of this study will increase knowledge that may help others in the future. Your participation will further understanding of Celiac disease and how its treatment affects close relationships. The information gained may help other people with Celiac in 
supporting a gluten free diet. In addition, as a thank you for participating in the study, a small donation will be made to the Celiac Disease Foundation (CDF).

What are you doing to protect me?

Your answers will be confidential, meaning none of your identifying information will be connected to your responses and only the research staff will be able to see what you mark down. Data from your survey will be stored in a secure computer file, identified with a code number.

\section{Any questions?}

If you have questions or concerns about the study itself, please contact Lindsey Alley at cdstudy@pdx.edu. If you have concerns or problems about your participation in this study or about your rights as a research subject, please contact the Human Subjects Research Review Committee, Office of Research and Sponsored Projects, 111 Cramer Hall, Portland State University, (503) 725-4288. You may also contact Dr. Cynthia Mohr by mail at the Department of Psychology, P.O. Box 751, Portland State University, Portland, OR 97207.

By clicking the button below you indicate that you have read and understand the above information and either do or do not agree to continue on to the survey.

$\square$ I agree to participate in the survey.

$\square$ I do not agree to participate in the survey.

*If participant indicates that they do not agree to participate, they will be forwarded to the end of the survey, which contains a quick "thank you" for their time. 


\section{Appendix C}

Emailed Invitation

Subject: Invitation to Participate in Celiac Relationship Study

Dear Sir or Madam,

You are invited to participate in a research study conducted by Dr. Cynthia Mohr and Lindsey Alley from the Department of Psychology at Portland State University (PSU). The researchers are interested in the diets of couples where at least one member has Celiac disease, and the types of interactions between both partners. The results of this study will be used to understand more about the eating behaviors and relationships of individuals with self- or medically-diagnosed Celiac.

The survey will take approximately 20 to 30 minutes to complete. Questions will focus on how you eat, your current relationship, and your thoughts about the gluten free diet. To participate, you and your significant other will need to be at least 18 years of age, and in a committed relationship of at least six months. Also, either you or your partner (or both) must be self- or medically-diagnosed with Celiac disease.

Simply click the link below, or cut and paste the entire URL into your browser, to access the survey.

\section{https://portlandstate.qualtrics.com//SE/?SID=SV_erDIIMjARHztrPn}

Your input is very important to us and will be kept strictly confidential, meaning it will be used only for the purposes of this research project. Neither your significant other nor the public will ever have access to your personal responses.

If you have any questions or concerns about the study, please contact Lindsey Alley at cdstudy@pdx.edu. You may also contact Dr. Cynthia Mohr by mail at the Department of Psychology, Portland State University, P.O. Box 751, Portland, OR 97207. 


\author{
Appendix D \\ Follow-up Emails
}

Recipient: Initial Repondent

Subject: Thank You for Participating!

Thank you for participating in our survey of Celiac couples! Your response is very important to us, and will help further our understanding of eating behaviors in Celiac relationships.

Your partner has just been emailed a link to the survey. You may want to remind them to participate if they want to. Thanks!

Let me know if you have any further questions about the study.

Recipient: Partner of Initial Respondent

Subject: Thank You for Participating!

Thank you for participating in our survey of Celiac couples! Your response is very important to us, and will help further our understanding of eating behaviors in Celiac relationships.

Let me know if you have any further questions about the study. 
Appendix E

Comprehensive List of Survey Measures

\begin{tabular}{|l|l|}
\hline \multicolumn{1}{|c|}{ Measures } & \multicolumn{1}{c|}{ Citations } \\
\hline Demographics & N/A \\
\hline Gluten Free Diet Adherence & Leffler et al., 2008 \\
\hline Celiac Dietary Adherence Test (CDAT) & Leffler et al., 2009 \\
\hline Motives for Sacrifice Scale & Impett, Gable, \& Peplau, 2005 \\
\hline Investment Model Scale (Satisfaction) & Rusbult, Martz, \& Agnew, 1998 \\
\hline Short Depression-Happiness Scale & Joseph et al., 2004 \\
\hline Primary Food Preparer & Nelson, Sapp, Berkman, Li, \& Sorenson, 2011 \\
\hline Communal Meals & Franks et al., 2012 \\
\hline Gluten Free Diet Attitude Scale & Sainsbury \& Mullan, 2011 \\
\hline Gluten Free Diet Knowledge Quiz & Leffler et al., 2008 \\
\hline Interpersonal Support Evaluation List (ISEL) & Cohen \& Hoberman, 1983 \\
\hline PAIR Inventory (Intimacy) & Schaefer \& Olson, 1981 \\
\hline Partner Support/Strain & Wallen \& Lochman, 2000 \\
\hline Marriage Role Expectation Inventory & Dunn, 1960 \\
\hline Subjective Health & Cockerham, Sharp, \& Wilcox, 1983 \\
\hline Note. Itlized & Sord \\
\hline
\end{tabular}

Note. Italicized measures not included in thesis analyses. 